\title{
VISUAL REPRESENTATIONS OF THE BODY IN GHINESE MEDICAL AND DAOIST TEXTS FROM THE SONG TO THE QING PERIOD (TENTH TO NINETEENTH CENTURY)
}

\author{
Catherine Despeux \\ Translated by Penelope Barrett
}

\begin{abstract}
This article is a preliminary survey of representations of the body produced in China from the Song to the Qing period in the context of medicine, forensic medicine and Daoism. Despite much common theoretical background, bodily representation in each of these fields differs in function and intent. Each field came to be associated with a particular aspect of the body. For medicine, this was the description of the viscera and the channels and tracts through which $q i$ and humours flowed; for forensic medicine, it was the description of the skeleton; for Daoism, it was the symbolic description of the body as the spatio-temporal locus of a system of mutations and correspondences with the outside world and the spirit world.

These representations fall into three categories, reflecting three different approaches to the body: images of the whole body approached from without, including gymnastic postures, locations on the body, somatic measurements, channels and tracts; images of the inside of the body, i.e. the internal organs and the skeleton (which raises issues regarding dissection); and images of the symbolic body, i.e. alchemical processes within the body and the true form of the allegorical body. The images, which are always accompanied by text, require to be read according to specific cultural codes, and reveal particular mental constructions of the body. They perform multiple functions, serving as proof of knowledge, teaching material, medium of transmission, memory aid, or graphic presentation of a text; and for the Daoists, manifesting the form of the true body.
\end{abstract}

Images of the body grow out of culture-specific ideas and experiences, both shared and individual. We divide up the world into discrete objects of knowledge and perception according to a set of concepts we carry with us. Thus, in order to grasp how other cultures have understood the representation of the body, and to see how they have translated that understanding into pictures and schemas 
that may differ radically from those that help form and inform our visual environment, we must first challenge our own preconceptions.

Before venturing on any comparisons, this paper will therefore begin with a survey of Chinese representations of the body, focusing on the ways in which these images were read as well as the context in which they were produced. It will examine graphic representations ( $t u$ 圖) in their own context, with particular regard to their function and use and their textual and intertextual environment. Using a range of examples of images of the body, and of processes that take place within the body or relate to it, it will analyse various possible functions of visual imagery, which are inseparable from mental representation itself. This will allow us to deduce certain characteristic features of concepts of the body in China.

Body imagery in art, though clearly relevant to this discussion, lies beyond the scope of the present paper, which will focus exclusively on medicine and Daoism. I will examine some representative examples of functionally distinct images, so as to highlight a number of issues relating to mental constructions and symbolic representations of the body in these two fields.

Each field came to be associated with a particular aspect of the body: for medicine, this was the description of the viscera and the channels and tracts through which $q i$ and humours flowed; for forensic medicine, it was the description of the skeleton; for Daoism, it was the symbolic description of the body as the spatio-temporal locus of a system of mutations and correspondences with the outside world and the spirit world.

The examples I will discuss, some of them figurative and some diagrammatic, date from the Song, Ming and Qing periods (eleventh-nineteenth century CE). This is largely a choice born of necessity, since so few images of the body survive from earlier periods, but it also reflects the expansion in the use of 'graphic representations' (tu) that occurred in the Song. I have attempted to formulate a typology of graphic representation for the areas outlined above. Three broad categories can be distinguished: the body in its entirety, bounded by an outline; the interior of the body or of body parts (the internal organs or skeleton); and symbolic representations of the body. 


\section{Representations of the whole body}

Representations of the whole body fall into five categories: 1. representations of gymnastic movements; 2. representations of landmarks on the surface of the skin, i.e. acupuncture and moxibustion locations; 3 . depictions of the paths of the channels and tracts; 4. representations showing the positions of the bones and somatic measurements, intended as a guide to the configuration and relative proportions of constituent elements of the body; 5 . representations used as official documents in forensic medicine, which were completed with coroners' autopsy notes.

The common feature uniting all these types of images is that the body-sometimes clothed and sometimes naked - is rendered in outline only, albeit with increasing sophistication. Elements inside the outline, if any, are confined to circles, black dots and simple lines. Measurements and proportions are not accurately reproduced. Often, though not always, the images bear captions.

\section{Representations of gymnastic movements (daoyin 誉引)}

The earliest known representations of gymnastic movements (daoyin) are contained in a silk scroll of the Han period (prior to $168 \mathrm{BCE}$ ), discovered in a tomb at Mawangdui, near Changsha (Hunan province). They consist of 44 full-length drawings of male and female bodies, clothed in garments of various styles and colours. ${ }^{1}$ After this, we find no further gymnastic images for more than ten centuries, even though we know from the bibliographic catalogues that they continued to be produced.

The first extant example from the Song period shows an eightmovement routine belonging to the Eight Brocade Method (baduan jin 八段錦). It is included in the thirteenth-century Daoist compilation Xiuzhen shishu ${ }^{2}$ 修真十書 (c. $1250 \mathrm{CE}$ ); since, however, this text is known only from the 1445 edition of the Daoist canon, we cannot tell for certain whether the drawings actually date from the thirteenth century, or whether they were added at some later date. Gymnastic images become increasingly common in the Ming period

1 On this subject, see Despeux 1989 and 2004; Harper 1998.

2 Daozang 263, Xiuzhen shishu, juan 19, 4a-5b. 
(fourteenth to seventeenth century), especially in learned works on the art of 'nourishing life' (yangsheng 美生), such as Zhou Lüjing's 周履 Bone Marrow of the Red Phoenix (Chifeng sui 赤栭睢) ${ }^{3}$ (late sixteenth century) or Hu Wenhuan's 胡交煥 Collected Texts on Longevity and Maintaining Life (Shouyang congshu 爵養叢書) (late sixteenth century). (See fig. 1)

These representations are undoubtedly more sophisticated and more elaborate than their Han counterparts; nonetheless they follow the same conventions and are codified in the same manner. They show clothed figures in a standing, seated or recumbent position, sometimes differentiated within the same set of drawings by hairstyle and facial expression. Almost all of them appear to be male, judging from their garments and more especially from their headwear and hairstyles. In some instances, the upper body is naked. The pictures are accompanied by text, either on the same page, above, beside or below the figure, or on the facing page. The intention seems to be essentially didactic; they provide the literate reader with a guide to the movements recommended to treat particular illnesses or to promote longevity. Most of the poses shown are static ones, to be held at length while the movements of inhaled air and internal forces do their work within the body. Kinetic poses are suggested by depicting a single stage in the course of a movement, but it would be impossible to execute the pose on the basis of this information alone, without verbal explanation. Here, the image is ancillary to the text; its function is to provide a schema enabling the user to orient his/her body in physical space.

\section{Representations of locations on the body}

In the field of medicine, we find representations of the body intended to show particular locations. These consist of a schematic outline drawing of a naked human figure, with a head, torso and four limbs. Acupuncture and moxibustion points are indicated by black or white circles, with captions giving their name or location.

The earliest surviving images of this kind are the moxibustion charts in the Tang medical manuscripts rediscovered at Dunhuang. ${ }^{4}$

\footnotetext{
3 Translated in Despeux 1988.

${ }^{4}$ Most of them are now in the Stein collection (S5737, S6168, S6262, P2675); compare Lo 2005.
} 

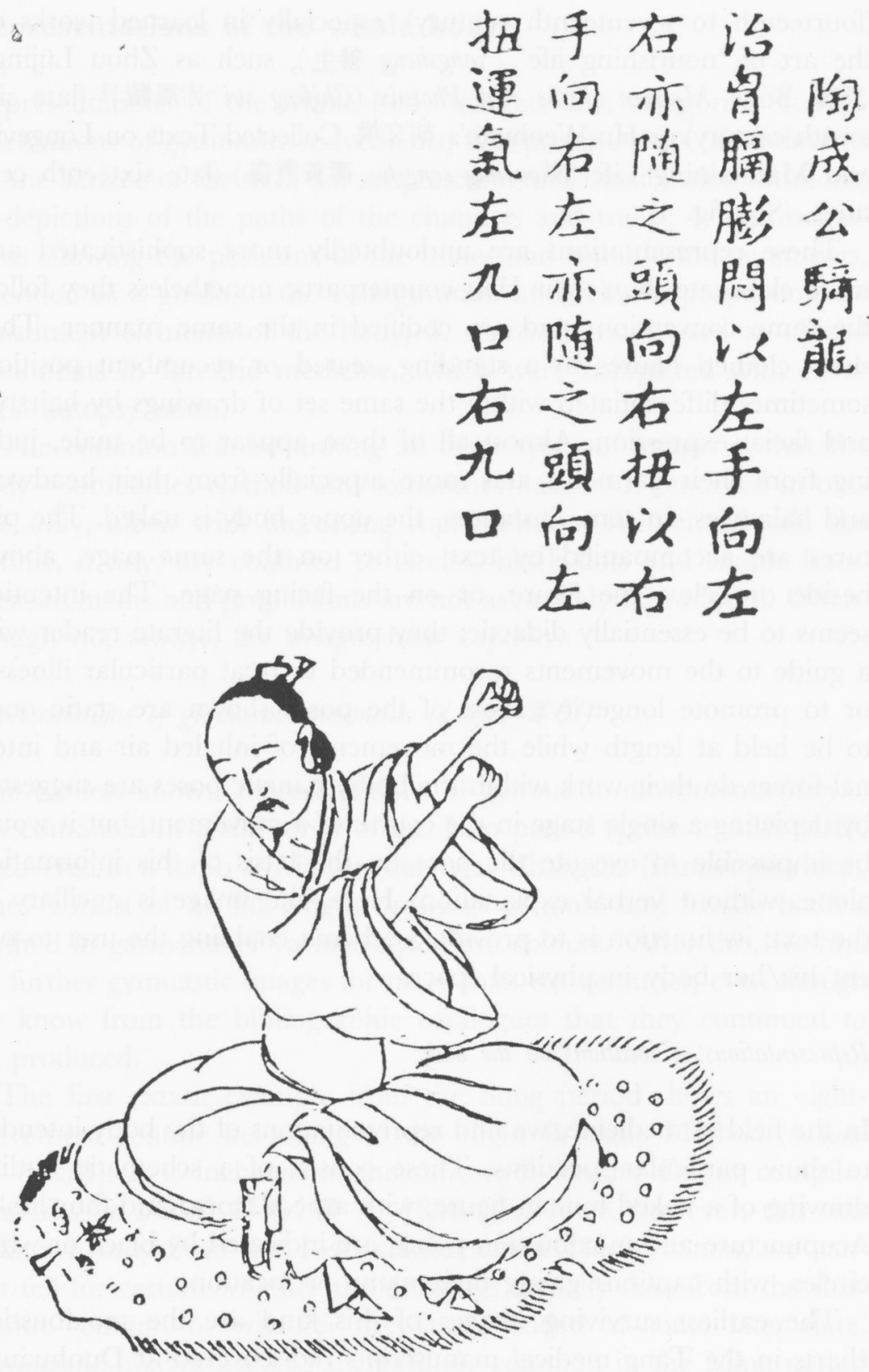

Fig. 1 Gymnastic pose

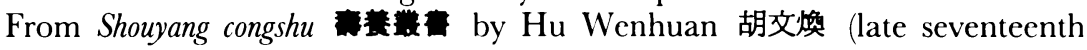
century). 
They have captions naming the moxibustion points and locating them with respect to external landmarks on the body (e.g. a point may be described as 'three inches (cun) below the navel', or 'on the inside of the lower knee'). This pattern persists into the Song, Ming and Qing periods in the literature of acupuncture and moxibustion, in parallel with the image type discussed below, where the points are shown strung out along lines representing the channels and tracts. ${ }^{5}$ The points marked within the outline of the body are connected by lines to the captions outside it. These labelled diagrams form a pendant to texts describing in greater detail the points themselves, their location and their therapeutic uses. So far as we can tell, they served as a visual aid, complementing and supporting the oral transmission of medical knowledge and the practical training received from a master, helping the apprentice physician to map the points on to physical space and to memorise their location. (See fig. 2)

Representations of the channels with acu-moxa points

Acu-moxa charts showing the channels with the points located on them constitute a very ancient form of medical representation of the body. Though no examples predating the Song period have come down to us, the bibliographic catalogues of the earlier Liang, Sui and Tang dynasties testify to their existence. ${ }^{6}$ Thanks moreover to the famous Tang physician Sun Simiao 孫思选 (581-682 CE), we possess precise information on the context in which these charts were created and the uses to which they were put. In his masterpiece Prescriptions Worth a Thousand Gold Pieces (Qianjin yaofang 千金䒚方) (c. $652 \mathrm{CE}$ ), he writes:

The practitioner can familiarise him/herself with the points through the engravings and find out their distances from one another from the

${ }^{5}$ Images of this type appear, for example, in Zhenjiu zisheng jing 針负资生經 by the Song author Wang Zhizhong 王執中 and in Zhenjiu jing 猃负經, an anonymous text of the Song period.

${ }^{6}$ For example, Suishu, juan 34, p. 1040, cites Mingtang kongxue tu, 3 juan 明堂孔穴 圆三卷; Xin Tangshu, juan 59, p. 1565, lists Qin Cheng zu mingtang tu, 3 juan 秦承 祖明堂瞦三; Huangdi shi'er jüngmai mingtang wuzang tu, 1 juan 黄帝十二經脈明堂 五 回一卷; Cao shi Huangdi shi'er jing mingtang yance rentu, 12 juan 曹氏黄帝十二經明堂優側 回十二卷; and Long xian su zhenjing bing kongxue hama tu, 3 juan 龍行素針經并孔穴䟺 蟆㖥三卷。 


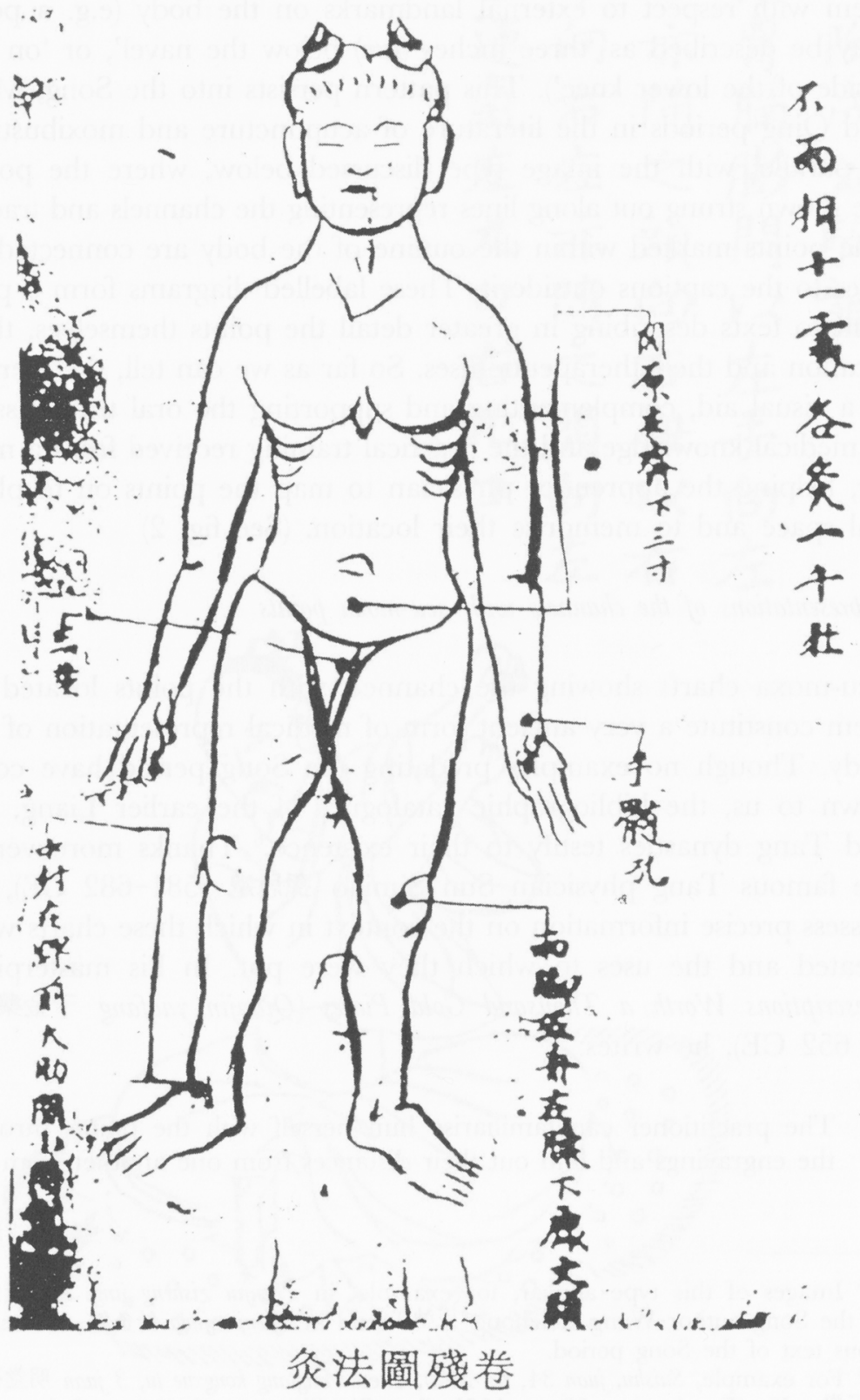

Fig. 2 Moxibustion points

From Jiu jing 炎經, anonymous, Song period. 
text; thus the doctor becomes imbued with the knowledge of them and can locate them effortlessly. Given the great antiquity of the old engravings of the Illuminated Hall (Mingtang 明堂圖), and the scribal errors that have crept in during the course of transmission, they can no longer serve as a guide. I have therefore followed the engravings recently made by the team of Zhen Quan 甄櫵. According to the Illuminated Hall Canon, the average height of a human being is 7 chi 尺 (feet), 8.4 cun $寸$ (inches). I drew the charts at half scale, giving a height of $3 \mathrm{chi}, 8.2 \mathrm{cun}$, so that the distance between the acupuncture points is half the actual distance and 5/10 cun represents 1 cun. For the chi, I adopted the ancient foot measurement of the Hous of Xia; in the Sima system, 6 chi equals 1 bu 步 (pace), which is the unit of measurement used in the Blue River and Huai River regions and the lands of $\mathrm{Wu}$ and Yue. Eight cun equals one small chi. ${ }^{7}$ The paths of the Twelve Channels are shown in five different colours and the Eight Extraordinary Channels are shown in green. Altogether, the three charts contain 650 points, distributed as follows: 282 points on the chart of the front of the body, 294 points on the chart of the back of the body and 174 points on the chart of the side of the body. There are 349 point names in total, comprising 301 double points and 48 single points. ${ }^{8}$

The introduction to the chapter on acupuncture, quoted above, is followed by a description of the locations and therapeutic uses of the acu-moxa points, classified according to the three charts. Text and images were evidently designed to complement each other; sadly, however, the latter have disappeared. Intended as a learning aid for the practitioner, they were devised with a concern for accuracy that emerges clearly from Sun Simiao's comments on the scale of his drawings. It seems safe to infer that these essentially didactic charts corresponded in intention and function to the representations we have looked at so far, with one key difference - by Sun Simao's own explicit admission, they possessed a normative value which is not

7 The current system of linear measurement is as follows: 1 cun $\mathrm{O}$ (inch) $=10$ fen 分; 1 chi (foot) $=10$ cun $; 1$ bu (pace) $=5$ chi. The cun is equivalent to $1 / 30$ metre. Systems of measurement have varied according to time and place. Formerly, the official system coexisted with those in use in the various markets. According to Tongiian waiji 通監外集, the chi was divided into 10 cun under Yu the Great, 12 cun under Tang, and 8 cun under King Wu of Zhou. In the Sima system, used in the Zhou period for measurements of area, $10 \mathrm{chi}$ were equivalent to one $b u$. It is interesting to find Sun adopting these ancient measurements, which were apparently still in use in some parts of China.

${ }^{8}$ Beiji qianjin yaofang, juan 29, p. 508; see also Despeux 1985, p. 134. 
evidenced in the preceding examples. We have no way of telling whether Sun Simiao produced them on his own initiative, or (as seems quite plausible) in response to an Imperial command. However, they were certainly known to the Tang Emperor Taizong, who is reported to have issued a decree banning the use of the bastinado when he was alerted to its dangers by viewing these very acupuncture charts. ${ }^{9}$

The relationship between text and visual representation $(t u)$ described above persisted into the Song period, when an official standardisation project was launched, involving not only charts of the body but also 'Bronze Man' figurines showing the channels and acu-moxa locations. ${ }^{10}$ Wang Weiyi 王惟一 is known to have composed his Acupuncture and Moxibustion Canon of the Bronze Man (Tongren zhenju jing 銅人針炎經) in $1026 \mathrm{CE}$, a year before the first Bronze Man was actually cast. These figurines had a pedagogical function in addition to their normative value, being used as a teaching aid at the Imperial College and for official examinations. It should be noted that the Bronze Man opened up to reveal a set of wooden viscera within. ${ }^{11}$ This initiative was followed by various other such projects in the course of the Song and Ming periods. ${ }^{12}$

The illustrations that have come down to us are either composite charts, offering an overview of several channels, or diagrams of individual channels. The engravings in Explanations of the Fourteen Channels (Shisi jing fahui 十四經發揮) by Hua Shou 滑壽 (ob. 1341) belong to the latter type. (See fig. 3) In this work, a description of each channel is followed by an illustration showing a human figure naked to the waist, the nether regions decorously covered by a loincloth or skirt. The channels are represented by lines drawn on the body, and on these the acu-moxa points are marked with little black or white circles. There are captions giving the point names but no other information. Each figure is drawn in a posture designed to show the course of the channel with maximum clarity, according to whether it runs along the inside or outside or outside of the limbs, for example.

As regards composite charts, one of the earliest extant examples

\footnotetext{
${ }^{9}$ See Sui Tang jiahua, p. 1 la.

${ }^{10}$ See also Goldschmidt 2004.

"See Ma 1993.

12 Ma 1993.
} 


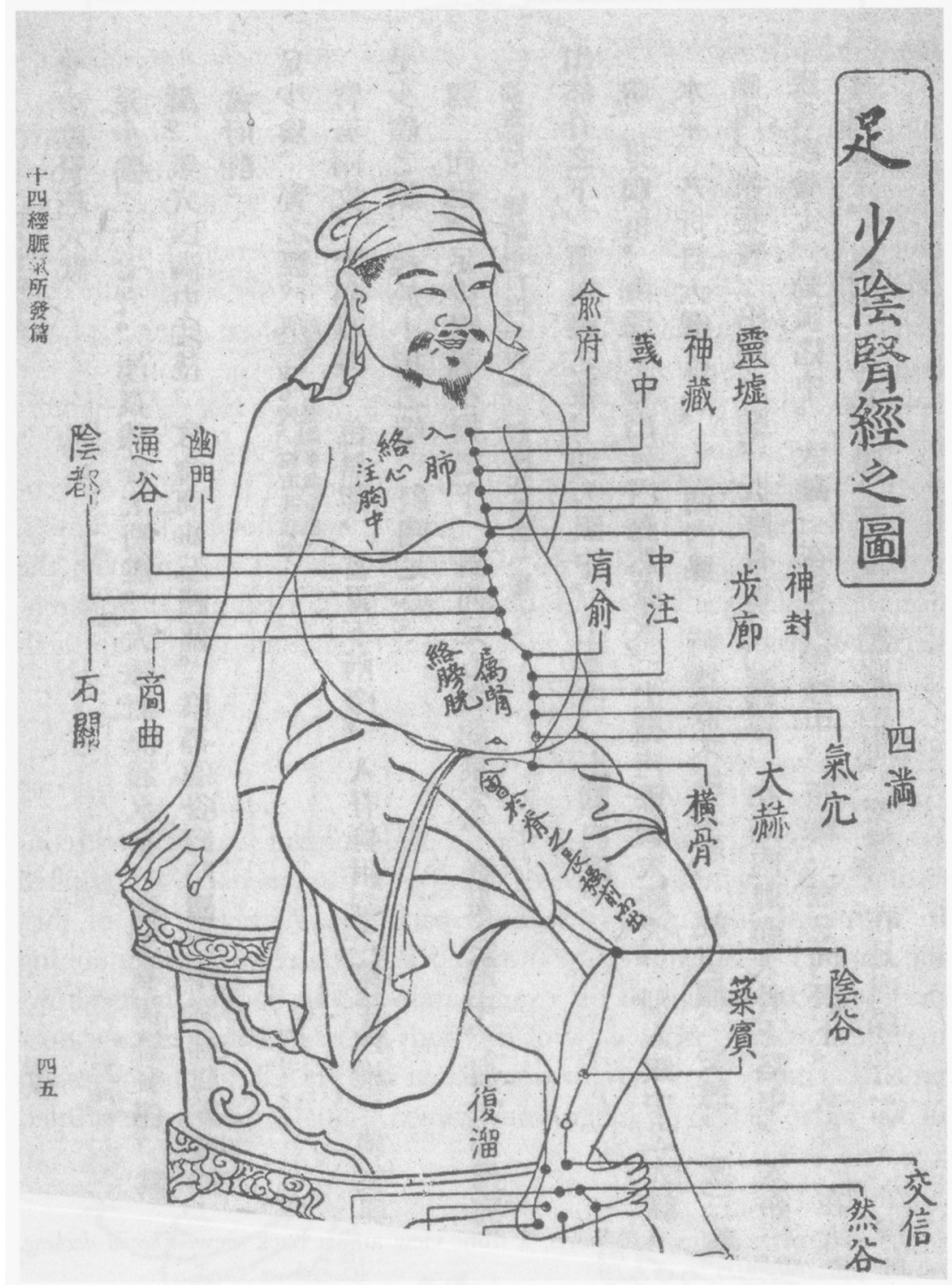

Fig. 3 Representation of an acu-moxa channel From Shisi jing fahui 十四經發揮 by Hua Shou 滑尋 (thirteenth century). 
is found in Compendium of Acupuncture and Moxibustion (Zhenjiu Dacheng 針炎大成) (1601 CE) ${ }^{13}$ by Yang Jizhou 楊継州. (See fig. 4)

Representations showing the positions of the bones and somatic measurements

Whereas the three types of representations discussed above have existed since antiquity, somatographic charts providing information about the relative proportions of the parts of the body and the distances between them are a more recent phenomenon. One of the earliest known charts of this kind dates back to the fourteenth century CE. ${ }^{14}$ From that time onward, we begin to see images of the body with inscriptions inside the outline, giving the names of the bones and their measurements according to the two relevant chapters of the Inner Classic of the Yellow Emperor (Huangdi neijing 黄帝內經). ${ }^{15}$ Such images become increasingly common in the late Ming (seventeenth century). ${ }^{16}$ These somatographic charts show a two-dimensional arrangement of a series of terms, which are also given in the accompanying text. They are clearly not to be read as a literal rendering of visible objects, but as a kind of mnemonic route-map facilitating the acquisition of knowledge.

\section{Forensic documents}

For forensic purposes, a special type of document was devised, consisting of a schematic outline drawing of a human body, to be filled in with notes on injuries, diseased parts etc. With the aid of this, the coroner was required to draw up a death certificate containing the main conclusions of his examination of the body. Charts showing the back and front view of the body were included in case documents. These charts were first circulated in $1211 \mathrm{CE}$ at the suggestion of Xu Sidao 徐似道, a judge from Jiangxi. Initially, they were printed

13 This work contains two charts, a front view and a back view. Zhenjiu dacheng, juan 6, pp. 189-90.

14 It is entitled 'Image of measurements on the recumbent person' (Yangren chicun zhi $t u$ 仰人尺寸之國) and is found in Shisi jing fahui 十四經蔡揮 by Hua shou 滑帚.

${ }^{15}$ Huangdi Neijing, Lingshu 1 雷樞, Chapter 14, 'Measurements of the Bones' (Gudu pian 骨度篇); Suwen 素閭, Chapter 60, 'Interstices of the Bones' (Gukong lun 骨空論).

${ }^{16}$ See for example Leijing tuyi 類經國買 by Zhang Jiebin 張介宾 (1624), Sancai tuhui 三才国會 (1607) by Wang Qi 王圻 and Wang Siyi 王思義 and the engravings edited in 1731 by Wuying dian 武英殿. 


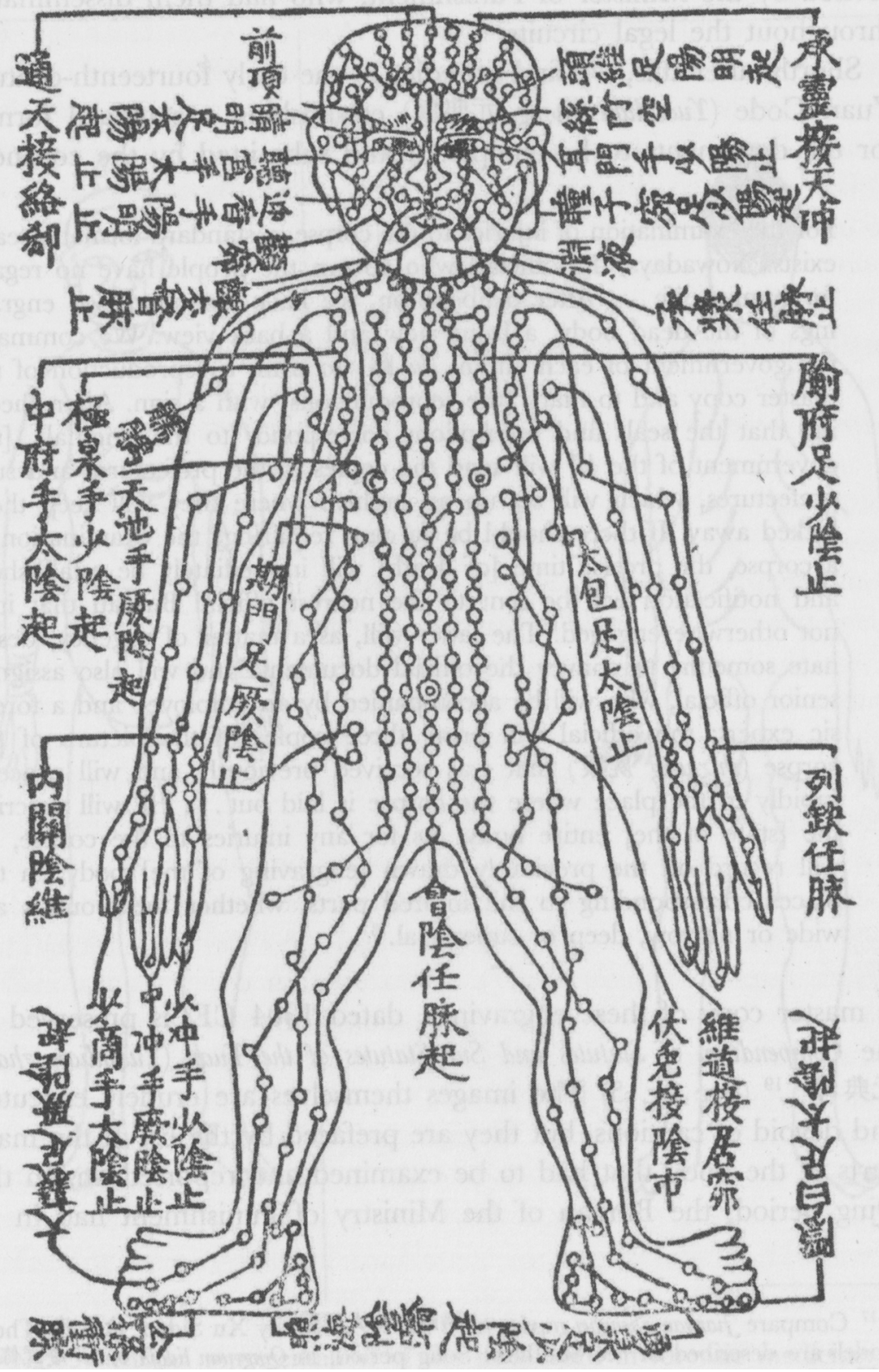

Fig. 4 Composite chart of the channels and tracts From Zhenjiu dacheng 針炎大成 by Yang Jizhou 楊緗洲 (1601). 
and distributed in Hunan and Guangxi. ${ }^{17}$ They were subsequently revised by the Minister of Punishment, who had them disseminated throughout the legal circuits.

Shortly after this, we find an edict in the early fourteenth-century Yuan Code (Yuandian zhang 元典章) establishing a standard format for the documents to be completed and submitted by the coroner.

For the examination of injuries to the corpse, a standard format already exists. Nowadays, the officials who govern the people have no regard for human life... After deliberation, we have instituted two engravings of the dead body, a front view and a back view. We command the government of each circuit ( $l u$ 路) to print a reproduction of the master copy and to mark [the reproductions] with a sign. After checking that the seals and inscriptions correspond [to the original], [the government of the $l u]$ will send the copies to the prefectures and subprefectures, which will set up an archive where they will keep them locked away. If there should be [a case requiring] the examination of a corpse, the precise time [of death] will immediately be established, and notification will be sent to the nearest official Bureau that it is not otherwise engaged. The latter will, as a matter of urgency, designate someone to convey the official documents and will also assign a senior official, who will be accompanied by an employee and a forensic expert; the official will bring three copies of the picture of the corpse (shizhang 屍帳) that was received previously and will proceed rapidly to the place where the corpse is laid out... He will describe the [state of the] entire body. As for any injuries to the corpse, he will record on the previously drawn [engraving of the] body, in the places corresponding to the injured parts, whether the wounds are wide or narrow, deep or superficial. ${ }^{18}$

A master copy of these engravings, dated $1304 \mathrm{CE}$, is preserved in the Compendium of Statutes and Sub-Statutes of the Yuan (Yuandian zhang 元典章). ${ }^{19}$ (See fig. 5) The images themselves are crudely executed and devoid of captions, but they are prefaced by the list of the main parts of the body that had to be examined and reported on. In the Qing period, the Bureau of the Ministry of Punishment had in its

${ }^{17}$ Compare Jianyan zhengbei renxing tu 检驗正背人形圆 by Xu Sidao 徐思道. These models are described in the Southern Song period, in Qingyuan tiaofa shilei 鹿元條法 事類. They are not the earliest known representations of the corpse; this work is predated by Jianyan gemu 驗格目 by Zheng Guangshang 鄚光 尚 (see Jia 1983, $4 / 1$, p. 7$)$.

${ }^{18}$ See Ratchewsky 1937, volume 4, p. 224.

19 Yuandian zhang, juan 43 on the Minister of Punishment, part 5 on homicide. 


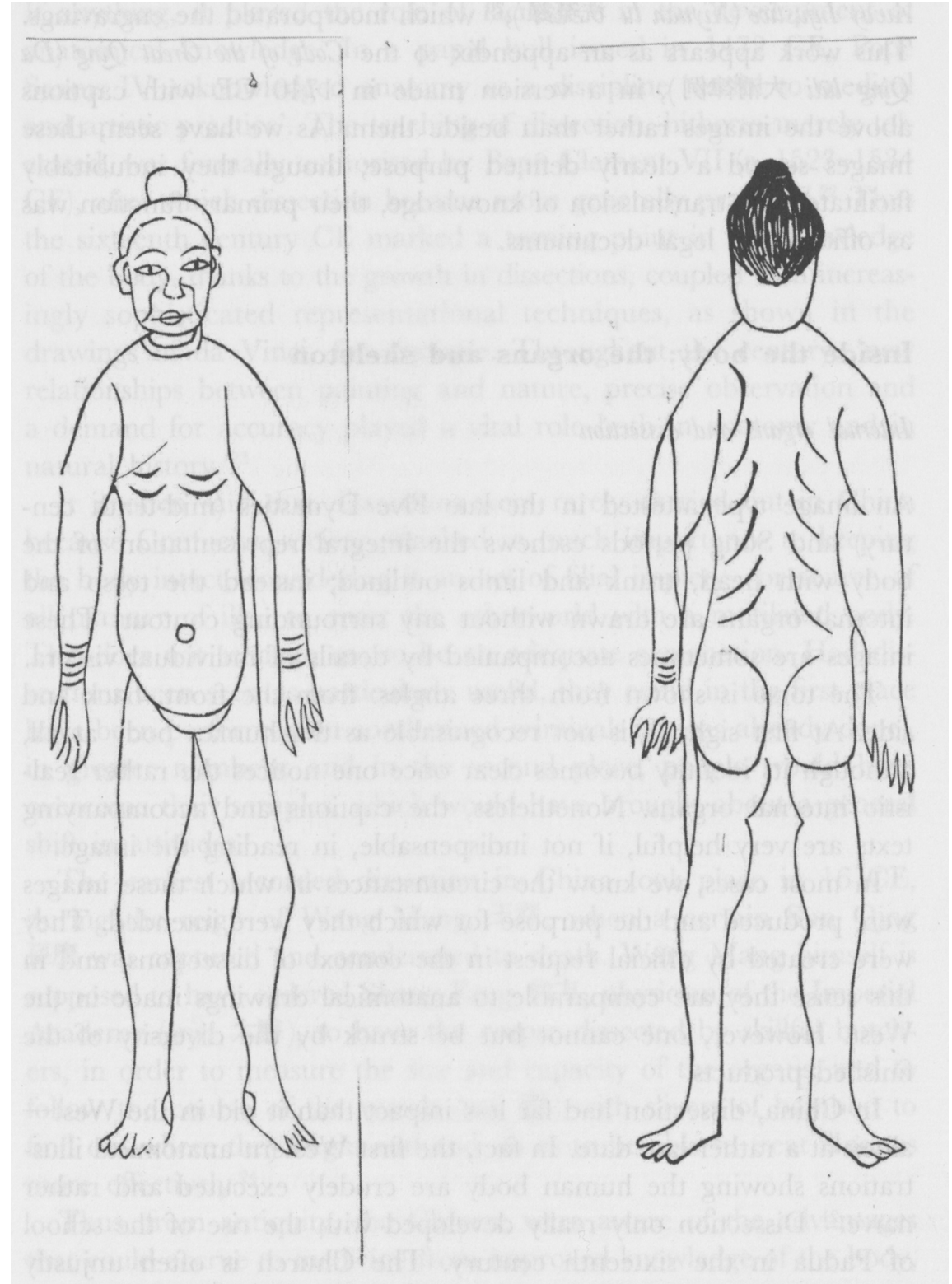

Fig. 5 Model representation of the body used in forensic medicine. From Yuandian zhang 元典章 (1322 CE). 
possession an official annotated edition of the Treatise for Washing Away Injustice (Xiyuan lu 洗冤錄) ${ }^{20}$ which incorporated the engravings. This work appears as an appendix to the Code of the Great Qing (Da Qing lüli 大清律例), in a version made in $1740 \mathrm{CE}$ with captions above the images rather than beside them. As we have seen, these images served a clearly defined purpose; though they indubitably facilitated the transmission of knowledge, their primary function was as official and legal documents.

\section{Inside the body: the organs and skeleton}

\section{Internal organs and dissection}

An image type attested in the late Five Dynasties (mid-tenth century) and Song periods eschews the integral representation of the body with head, trunk and limbs outlined; instead the torso and internal organs are drawn without any surrounding contour. These images are sometimes accompanied by details of individual viscera.

The torso is shown from three angles: from the front, back and side. At first sight, it is not recognisable as the human body at all, although its identity becomes clear once one notices the rather realistic internal organs. Nonetheless, the captions and accompanying texts are very helpful, if not indispensable, in reading the image.

In most cases, we know the circumstances in which these images were produced and the purpose for which they were intended. They were created by official request in the context of dissections, and in this sense they are comparable to anatomical drawings made in the West. However, one cannot but be struck by the diversity of the finished products.

In China, dissection had far less impact than it did in the Westalbeit at a rather late date. In fact, the first Western anatomical illustrations showing the human body are crudely executed and rather naïve. ${ }^{21}$ Dissection only really developed with the rise of the school of Padua in the sixteenth century. The Church is often unjustly

${ }^{20}$ Lüliguan jiaozheng Xiyuan lu 律例校正洗冤錄 in 4 juan, dated 1694 (ed. Fu Sinian).

${ }^{21}$ Grmek and Bernabeo 1997, pp. 10-11. 
accused of preventing dissections, but this was by no means the case. If anything, it played the role of facilitator in the development of anatomical knowledge. In a papal bull issued in $1472 \mathrm{CE}$, Pope Sextus IV acknowledged anatomy as a discipline 'useful to medical and artistic practice'. The teaching of dissection, hitherto merely tolerated, was formally authorised by Pope Clement VII (r. 1523-1534 $\mathrm{CE})$, after which dissection became more generally practised. ${ }^{22}$ Thus the sixteenth century CE marked a turning point in the knowledge of the body, thanks to the growth in dissections, coupled with increasingly sophisticated representational techniques, as shown in the drawings of da Vinci, for example. Throughout the century, 'new relationships between painting and nature, precise observation and a demand for accuracy played a vital role both in anatomy and in natural history. ${ }^{23}$

It is often said that dissections were rarely carried out in China because Confucian society attached so much importance to keeping the body intact, considering it an act of filial impiety - or source of all manner of ills - to enter the otherworld with a mutilated body. This does not seem to me to be an adequate explanation. Had dissections been seen as particularly useful, they could in the first place have been performed on condemned criminals (as was already done), in greater numbers; and in the second place, people would have overcome their scruples, which would have brought about a general shift in attitudes.

The earliest recorded dissection in China took place in $16 \mathrm{CE}$, during the reign of Wang Mang 王茾, when a certain Sun Qing 孫慶 was captured and condemned to death. Wang Mang himself is supposed to have ordered Shang Fang 向方, physician of the Imperial Academy (taiyi 太醫), to have the corpse dissected by skillful butchers, in order to measure the size and capacity of the organs, and to follow the course of the vessels (mai 脈) with slivers of bamboo to find out where they begin and end, so as to be able to treat illnesses more effectively. ${ }^{24}$

Thus, from antiquity, the Chinese were aware of the advantages that could accrue to medicine from improved knowledge of the body,

${ }^{22}$ Grmek and Bernabeo 1997, p. 8.

${ }^{23}$ Grmek and Bernabeo, 1997, p. 11.

${ }^{24}$ Hanshu, juan 99, biography of Wang Mang 王芒, p. 4145. 
and of the progress that could thereby be achieved in treating disease. Nonetheless, we have no definite evidence of any further dissections until $1041 \mathrm{CE}$, even though it is likely that others took place in the intervening centuries. For instance, Hua Tuo 華佗 (?-208? CE), the personal physician of Cao Cao 曹操, father of the future ruler of Wei, may well carried out dissections, ${ }^{25}$ and if so, he would presumably have done so in an official capacity.

In $1041 \mathrm{CE}, 56$ rebels led by Ou Xifan 歐希范 were captured and put to death by Du Qi 杜杞, the Imperial Commissar (anwushi 按無史) charged with pacifying the circuits of Guangnan and Guangxi. $\mathrm{He}$ had their abdomens dissected and directed an official of the Prefecture called Wu Jian 吳簡 (or Lingjian 㗊簡 according to some sources) to commission artists to make drawings of the internal organs. These were published as Images of the Five Viscera of Ou Xifan (Ou Xifan wuzang tu 歐希范五澸圖). These events are described by several contemporary writers, ${ }^{26}$ and Shen Gua 沈括 (1033-1097 CE) criticizes the drawings and points out an error in them, ${ }^{27}$ implying that he actually saw them. This dissection, like the one ordered by Wang Mang in the Han period, was carried out by official command on the bodies of war criminals. The crucial difference is that it was attended not only by doctors but also by officials and artists, who were required to draw the internal organs. Regrettably the drawings have not survived.

Another series of dissections took place in the Chongning 崇密 era (1102-1106 GE) under similar circumstances, and once again

${ }^{25}$ A text entitled Hua Tuo neishi 華陀内視 is listed in the Liang catalogue (see Suishu, juan 34, p. 1041). In the opinion of Ma Jixing, it is the work of one of Hua Tuo's disciple, and neishi signifies 'observe and examine the form of the internal organs', indicating the practice of dissection. See Ma Jixing 1990, p. 136.

${ }_{26}$ The sources are: Dongzhai jishi, juan xia; Mengqi bitan, juan 26, art. 480, pp. 827-829; Yanxia fangyan, ed. in Shuofu, juan 29, vol. 5; Bintuilu, ed. in Shuofu, p. 234,

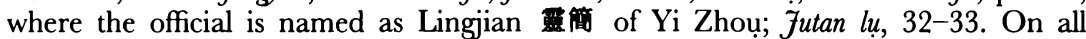
these sources, see Okanishi 1958, p. 297.

${ }^{27} \mathrm{He}$ writes: 'Human beings are said to have three orifices in the throat: one for fluids, one for solid food and the third one for air. This is completely wrong. The true images of the five viscera of Ou Xifan, which are widely transmitted, do indeed contain drawings of three orifices. Probably the examination was not carried out thoroughly enough. Solid and liquid foods are actually swallowed simultaneously, so how could they possibly enter the gullet separately? In fact, the human body has only two orifices [in the throat]: the larynx (yan 咽) and the pharynx (hou 喉). The pharynx is the conduit for liquid and solid foodstuffs, and the larynx allows air to enter...' Mengqi bitan, juan 26, art. 480, pp. 827-9. 
anatomical drawings were made. In Sizhou 泗州 (in the modern province of Jiangsu), a group of rebels were executed, and the Prefect Li Yuxing 李夷行 summoned doctors and artists to examine the bodies. They dissected the tissues, removed the diaphragm and sketched the curves and meanders of the inside of the body. They were allowed to examine and draw everything in detail. Yang Jie 楊介, a famous doctor from Sizhou ${ }^{28}$ known to have treated the Emperor Huizong ${ }^{29}$ (r. 1101-1125 CE), corrected the engravings from the original drawings and pronounced them far superior to those that stemmed from the Ou Xifan dissections. ${ }^{30}$ In the preface by Jia Weijie 賈偉節 of Luoyang to Yang Jie's Cunzhen huanzhong tu 存真環中圖 (1118 CE), we read:

Yang Jie, styled Jilao 吉老, observed and drew the actual form of the five viscera. He examined the depictions of the viscera made by Yanluozi 洷雚子, arranged and amended them; he then added the twelve channels and entitled his work Cunzhen huanzhong 存真環中. ${ }^{31}$

These images by Yanluozi-the 'Master of the Smoke Curtain'who was active during the Tianfu era (936-941 CE) of the Later Jin dynasty, ${ }^{32}$ are preserved in the thirteenth-century Daoist encyclopedia Xiuzhen shishu 修真十書 (c. 1250). ${ }^{33}$ (See fig. 6) There are six of them, including, notably, a front view and a back view of the trunk and its viscera. Their titles contain the term neïing 內境 [internal view, inner landscape, inscape], and they were presumably intended for people who practised the inward visualisation of the internal organs (the images are accompanied by a text by Yanluozi on inward contemplation, neiguan 內觀). We know nothing of the background to the creation of these images, which are exactly reproduced in an illustrated commentary on the Canon of Eighty-One Problems [in the Inner Canon of the Yellow Lord] (Bashi yi nan jing 八十一难经) by Li Jiong 李駧 (1269 CE). ${ }^{34}$ They coincide with Yang Jie's engravings

${ }^{28}$ See Gujin yitong daquan, juan 1. Compare Xu wenxian tongkao.

${ }^{29}$ See $X u$ wenxian tongkao.

${ }^{30}$ This is recorded in Junzhai dushu houzhi 郡栾買晴後志, juan 2, p. 31a-b (in Siku quanshu, 674, pp. 405-6).

${ }^{31}$ Miyashita Saburo 1968, pp. 148-9.

${ }^{32}$ See Chen 1963, p. 284.

${ }_{33}$ Dz. 263, Xiuzhen shishu, juan 18, 2a-3b.

${ }^{34}$ Huangdi bashiyi nanjing zhuyi tuxu lun 黄帝八十一難經註義圆序論 preserved in the Daoist Canon, $D z .1024$. 




Fig. 6 Representation of the trunk and its organs according to Yanluozi From Xiuzhen shishu 修真十書 (c. 1250), Dz 263, juan 18. 
in all respects but one, which is however extremely significant: the liver is shown on the left, in keeping with the theory of correspondences with the Five Agents and Five Directions, whereby the liver corresponds to 'spring' and 'the left'. Yang Jie placed the liver on the right after attending dissections; this is one of the amendments to which Yang Jie alludes in the preface quoted above.

It is worth noting that a text entitled Treatise on the Internal View [of the Body] According to Intendant Zhu (Zhu tidian neijing lun 朱提點內境論) appears directly after Yanluozi's work. The unknown author, who probably lived during the Song period, prior to $1250 \mathrm{CE}$, seems to have seen examples of anatomical drawings of dissected bodies. In his treatise, he states that the therapeutic location for the liver is the left, but the liver itself is located on the right (qi zhi zai zuo, qi wei zai you 其治在左, 其位在右). He draws a comparison with the images of Yanluozi, which he says tally with his own observations. He adds that the bodies of criminals have recently been dissected and examined in the market places, making it possible to ascertain that the throat does not, as erroneously supposed, contain three orifices, one for fluids, one for solid food and one for air. ${ }^{35}$

Yang Jie's images of the viscera were incorporated into a version of Hua Tuo's Chart of Inner Contemplation [of the body] According to the Mystery School (Hua Tuo xuanmen neizhao tu 華 陀玄門內照圖) published by Sun Huan 孫焕 in 1273 CE. (See fig. 7) This work was composed in $1095 \mathrm{CE}$ by Shen Zhu 沈銖, a proofreader in the Imperial library and archives, and subsequently appeared under various titles. Though no editions survive from before the Ming dynasty, they become plentiful from that period onward, indicating that the text enjoyed wide currency. Indeed, Wang Huling 汪琥苓 of $\mathrm{Wu}$ (Suzhou) writes in his preface of $1668 \mathrm{CE}$ :

For a long time, this work was conserved in the Palace, and few people were able to consult it. But in the Jiajing era (1522-1566 CE), an administrative assistant of the Imperial Academy of Medicine named Zhou Yuguo 周與國 made a copy of it, which he kept secretly at his home. From his grandchild Zhou Daozhou 周道州, I obtained a copy which was in poor condition and not easily legible. The book was in four juan, the first two containing Hua Tuo's work, and the second two containing additions by Guo 郭 and $\mathrm{Yu}$ 禹. ${ }^{36}$

${ }^{35}$ Dz. 263, Xiuzhen shishu, juan 18, 3b-5b.

${ }^{36}$ See the manuscript edition preserved in Zhongyang tushuguan 中央圆费館, Taiwan. See also Daozang jinghua, vol. 14-2. 


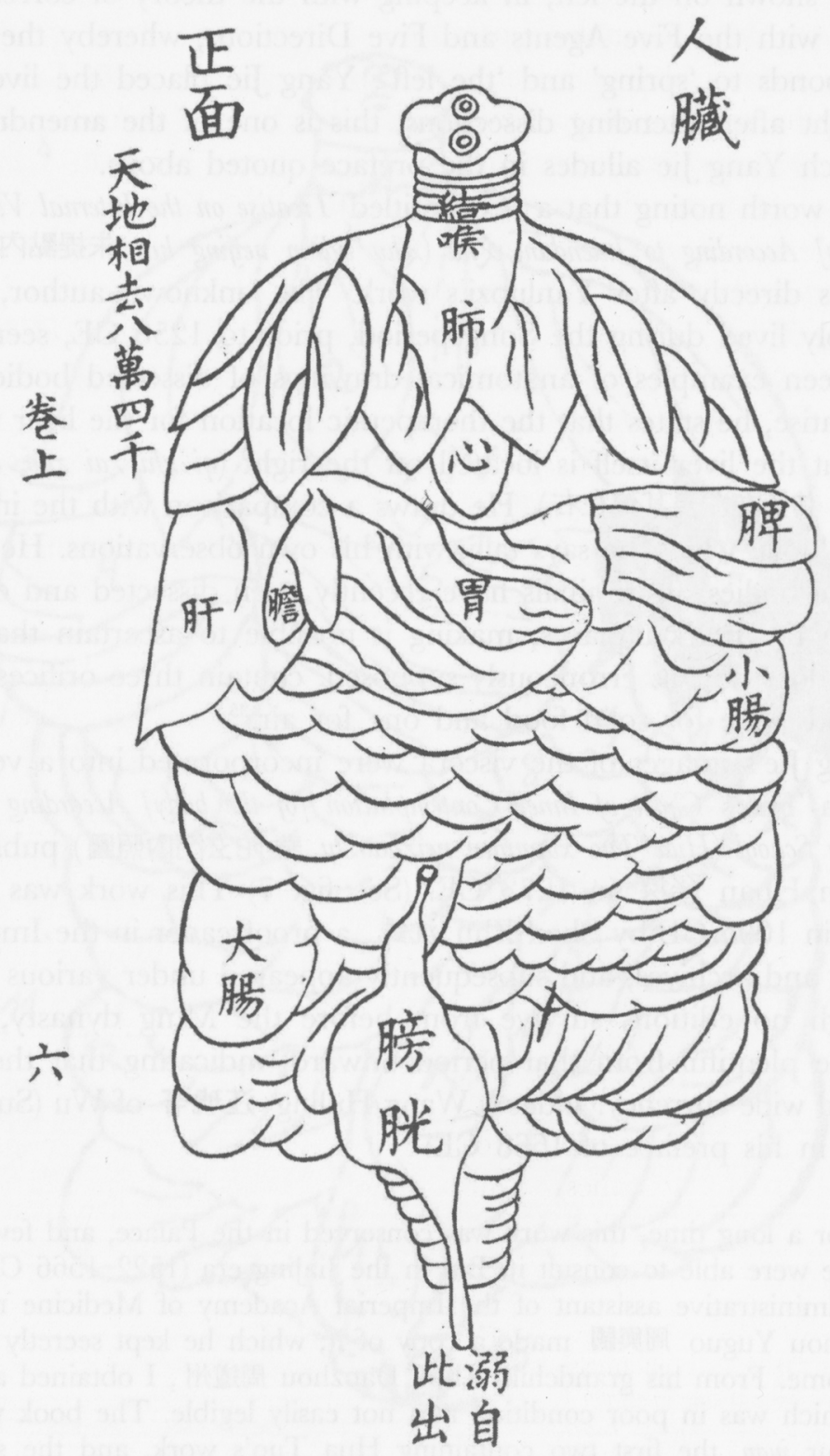

Fig. 7 Representation of the trunk and its organs

From Hua Tuo xuanmen neizhao tu 華陀玄門內照 (thirteenth century). 
It should be noted that Yang Jie's images were republished in Japan in 1304, in Ton-isho 頓豎鈔 by Kajiwara Seizen 椲原性全. ${ }^{37}$

In these images, unlike those of Yanluozi as reprinted in Nanjing tuyi, the liver is shown in its proper place, on the right. The first part of the text seems to have been written as a commentary on the Ou Xifan engravings; it criticises and seeks to rectify the current state of anatomical knowledge on three main counts.

The first criticism of traditional ideas echoes that of Shen Gua: there are only two orifices in the throat, whereas the Ou Xifan engravings show three. ${ }^{38}$ We might note here that Shen Gua justifies his assertion by reasoned argument: it would be mechanically impossible to keep solid food and liquids apart, and therefore there cannot be two separate orifices for them. The second criticism relates to the position of the liver: Hua Tuo's Chart of Inner Contemplation [of the body] According to the Mystery School states, without further explanation, that the liver is located on the right, in front of the right kidney and beside the stomach. ${ }^{39}$ The third criticism concerns the kidneys: in the engravings, they are shown higher in the body than the traditionally accepted location - instead of being low down and close to the sides, they are underneath the diaphragm, right next to the middle of the spinal column; and they are surrounded by a membrane with two vessels, the upper one connected to the heart and the lower one joining the two kidneys together.

Sometimes quite separately and sometimes in conjunction with these global representations of the trunk, we also find depictions of the individual viscera. They are attested in the Tang period (seventh-tenth century CE), i.e. even earlier than the former type of image. The bibliographic catalogue of the History of the Tang lists the titles of five sets of illustrations of the viscera, all of which are repeated in the Song bibliographies. ${ }^{40}$ Only one of them is still extant: Illustrations

${ }^{37}$ In Chapter 44 of this text, preserved in Neikaku bunko in Kyoto, we also find images of the twelve channels and the viscera after $\mathrm{Wu}$ Jian 吳简.

${ }^{38}$ Hua Tuo xuanmen neizhao $t u$, p. 7 a.

39 Hua Tuo xuanmen neizhao tu, p. 8b.

40 These are: Wuse bangtong wuzang tu 五色傍通五䑏国 by the Tang author Pei Wangting 裴王廷, catalogued in Tangshu, medical section (juan 59, p. 1571), Chongwen zongmu, juan 3, medical section 3, Tongzhi yiwenlüe (with the author named as Pei Guangting 裴光廷, and Songshi yizenzhi; Wuse bangtong mingiian tu 五色傍通明監四 by Pei Yuanling 裴元重 in 1 juan, listed in Chongwen zongmu and Tongzhi yiwenlüe, with the author named as the Tang Daoist Pei Xuanling 裴玄畨Wuzang bangtong daoyang 
of the Reinforcement and Purging of the Organs According to the Tradition of the Yellow Court (Huangting wuzang liufu buxie tu 黄庭五䑏六腑補渇回) (preface of $848 \mathrm{CE}$ ) by Hu Yin 胡愔, preserved in the Ming Daoist canon. The author, a female Daoist of the Shangqing sect, states in her preface that she has consulted various depictions of the viscera. ${ }^{41}$ The text gives a rudimentary anatomical account of the viscera, based on the ancient medical texts, chiefly the late Han Canon of Problems (Nanjing). However this merely serves as an introduction to her main subject: the spirits which reside in the organs according to the Shangqing tradition and which the adept must visualise and inwardly nurture, to maintain good health and achieve longevity. Strangely enough, although the author is at pains to point out that she has consulted several depictions of the viscera, the existing version of the text contains no images.

During the Song period, drawings of individual viscera are associated with dissections and are found in conjunction with general views of the trunk and its viscera, especially those from Hua Tuo's Chart of Inner Contemplation [of the body] According to the Mystery School, which were recycled without major changes throughout the Ming and the Qing. ${ }^{42}$ (See fig. 8) These images are particularly elaborate in their treatment of the connections and junctions between organs, illustrating an attempt to reflect upon and reproduce physiological mechanisms.

These same images of the viscera reappear, with a few variations, at the end of the seventeenth century in Origins of medicine (Yixue yuanshi 㯺學 原始) by Wang Honghan 王宏韓 (fl. 1688-1692 CE). Thus, despite the growth of dissection in the Ming period, and despite the spread of Western anatomical knowledge, rudimentary though this may have been, the format remained substantially unchanged right up until the beginning of the nineteenth century.

It was not until the early nineteenth century that the images were revised and various errors were amended in Corrections of the Errors in the Forest of Medicine (Yilin gaicuo 醫林改錯) (1822 CE), in light of Western anatomical science and the results of further dissections

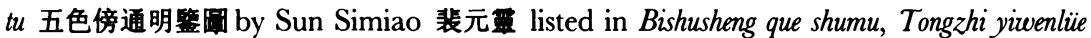
and Songshi yiwenzhi; and Huangting neijing wuzang liufu tu 黄庭内景五膡六腑回, by the Tang author Hu Yin 胡愔, the only one to have survived.

${ }^{41} \mathrm{Dz} 432$, Huangting wuzang liufu buxie tu 黄庭五䑏六腑補演國, 2a.

${ }^{42}$ See for example Sancai tu hui 三才圖會 (1607) and Leijing tuyi 類經回累 (1624) by Zhang Jiebin. 


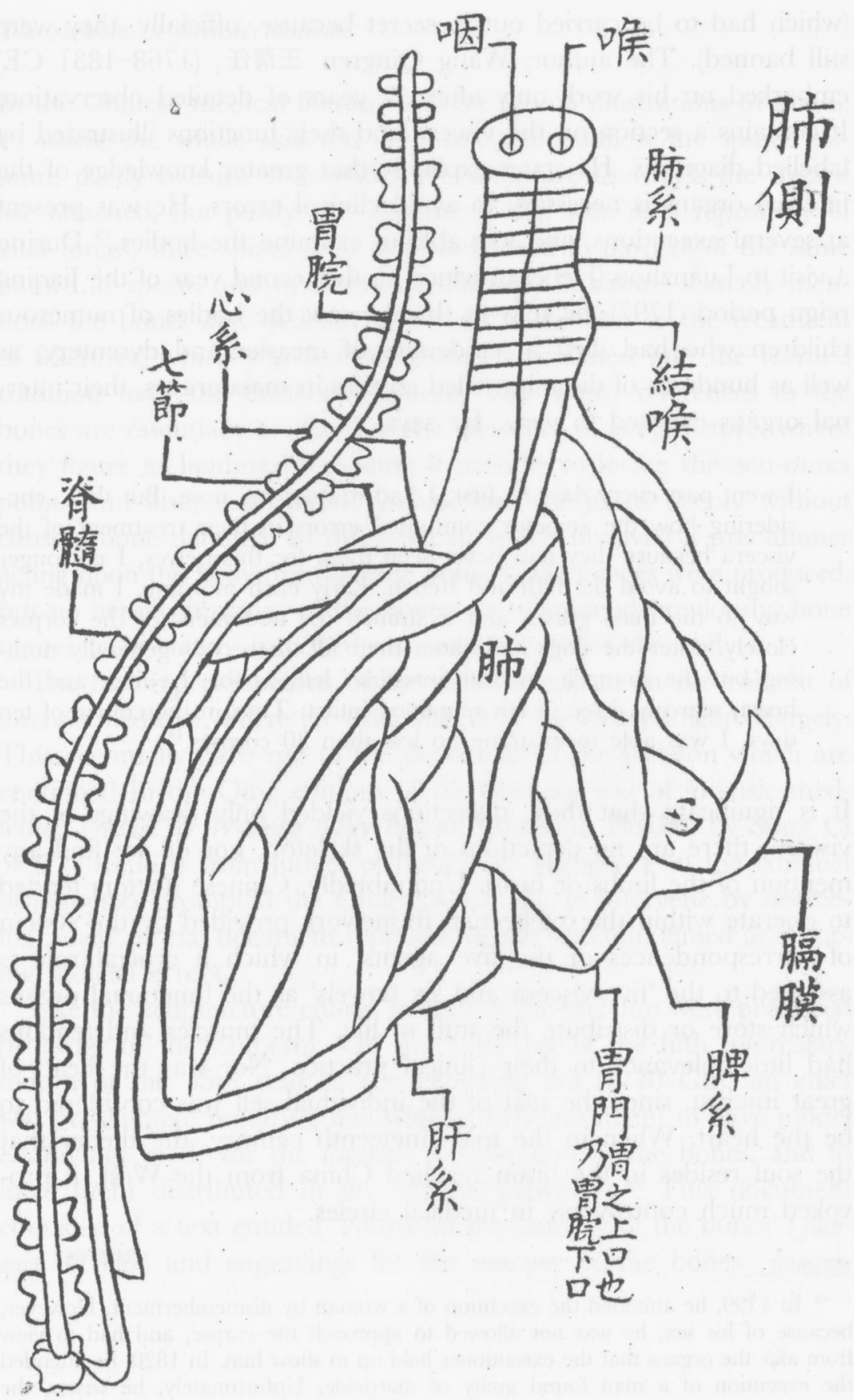

Fig. 8 Representation of an individual internal organ (the lung). From Hua Tuo xuanmen neizhao tu 華陀玄門內照圆 (thirteenth century). 
(which had to be carried out in secret because, officially, they were still banned). The author, Wang Qingren 王清任, (1768-1831 CE) embarked on his work only after 42 years of detailed observation. It contains a section on the viscera and their functions illustrated by labelled diagrams. He states explicitly that greater knowledge of the internal organs is necessary to avoid clinical errors. He was present at several executions, and was able to examine the bodies. ${ }^{43}$ During a visit to Luanzhou (Hebei province) in the second year of the Jiaqing reign period (1797), he tells us that he saw the bodies of numerous children who had died in epidemics of measles and dysentery, as well as hundreds of disembowelled corpses in mass graves, their internal organs exposed to view. He says:

I went past every day. At first, I had to hold my nose. But then, considering how the ancients committed errors in their treatment of the viscera because they had never seen them for themselves, I no longer sought to avoid the filth and stench. Early each morning, I made my way to the mass graves and examined the abdomens of the corpses closely. After the dogs had eaten their fill, there was generally nothing but the stomach and the intestines left; as for the liver and the heart, scarcely three in ten remained intact. Thus in the course of ten days, I was able to examine no less than 30 corpses. $^{44}$

It is significant that these dissections yielded only drawings of the viscera; there are no depictions of the skeleton, nor do we find any mention of the limbs or head. Undoubtedly, Chinese doctors tended to operate within the intellectual framework provided by the system of correspondences of the five agents, in which a crucial role is assigned to the 'five viscera and six bowels' as the functional organs which store or distribute the stuff of life. The muscles and tendons had little relevance to their clinical practice. Nor was the head of great interest, since the seat of the individual self was considered to be the heart. When in the mid-nineteenth century, the theory that the soul resides in the brain reached China from the West, it provoked much controversy in medical circles.

${ }^{43}$ In 1799 , he attended the execution of a woman by dismemberment. However, because of his sex, he was not allowed to approach the corpse, and had to view from afar the organs that the executioner held up to show him. In 1820, he attended the execution of a man found guilty of matricide. Unfortunately, he writes, the diaphragm tore before he had time to examine it. See Unschuld 1985, pp. 212-13.

${ }^{44}$ Tilin gaicuo. 
The skeleton in forensic medicine

In the Chinese medical literature, there are no illustrations of bones, let alone the whole skeleton. The one exception is the spinal column; partly because it provides the armature to which the organs are attached, but partly also because it was seen as a repository of vital forces, since spinal fluid was considered to partake of the same nature as sperm and brain tissue. Therapy literature scarcely mentions the bones and skeleton, not even in relation to the treatment of fractures, which was not completely assimilated into the learned tradition until the thirteenth century CE. Thus, references to the bones are essentially confined to the literature of acupuncture, where they figure as landmarks, making it possible to locate the acu-moxa points and also, if required, to puncture the joints deeply without causing bone damage. In this context, which involved a practitioner acting upon the body from outside, some visual images were produced, but no actual drawings of the bones; as mentioned previously, bone names were simply inscribed on various parts of the body.

The first representations of the skeleton appear in the context of forensic medicine, where the examination of the skeleton figured largely. This eventually gave rise to the depictions of the skeleton which are contained In the Qing editions of the essential text of forensic medicine, Treatise for Washing Away Injustice (Xiyuan lu 洗冤錄) by Song Ci 宋慈. ${ }^{45}$ Reports from judges of fraud and negligence in the conduct of autopsies prompted the Qing government to intervene by decreeing a new official document representing the skeleton, aimed at reducing judicial errors.

Like the acupuncture charts, images of the skeleton were produced by order of the Emperor. On the 19th day of the fifth intercalary month of the 35th year of the Qianlong era $(1770 \mathrm{CE})$, an edict was proclaimed, requiring the Minister of Punishment to have model engravings made for the forensic examination of the bones, and to have them distributed in the various provinces. ${ }^{46}$ This document consisted of a text entitled 'Norm for the autopsy of the bones' (jianguge 檢骨格) and engravings for the autopsy of the bones (jiangutu

${ }^{45}$ See Xiyuan lu, Chapter 29, juan 4.

${ }^{46}$ See Chongkan buzhu Xiyuan lu jizheng, juan 5, 15a-19b. 
檢骨國). The latter were probably printed in the Hall of Martial Valour (Wuyingdian 武英殿) in the Emperor's Palace, which functioned as the imperial press. Four acupuncture charts, one including depictions of the viscera, had already been printed here in $1731 \mathrm{CE}$; and in $1742 \mathrm{CE}$, it saw the publication of The Bronze Mirror of Medicine (Yizong yindian 硻宗金塹), a medical encyclopedia compiled by the Imperial Academy of Medicine, which is referred to in Qing commentaries on the Treatise for Washing Away Injustice.

This project was set in train by Zeng Fu 增福, a provincial judge from Anhui. Having noted that coroners' reports were often falsified, and in view of the rapid onset of putrefaction, he submitted a memorial to the Emperor requesting the provision of a standard chart of the skeleton with the status of a legal document, to curb fraudulent practices. Apparently, Zeng Fu was personally entrusted with the task of devising the engravings and the accompanying text describing the skeleton, which he accomplished with the help of a team of experts:

In the 35th year of the Qianlong era, the provincial judge of Anhui received the imperial command to publish standard engravings for the autopsy of the bones, and to have them appended to the Treatise for Washing Away Injustice. . . The plates are not the work of a single individual, and since each member of the team followed a particular master, opinions differed on some points. ${ }^{47}$

The earliest known exemplar was edited by a certain Wang Youhuai 王又棵 (1796 CE). (See fig. 9) The bones are roughly drawn, and are separated from one another, giving the impression that they have been found scattered at the scene of a crime and reassembled. There are captions written on the larger bones and beside the smaller ones, connected to them by lines. In some places, it is possible to see small white circles, which have been interpreted by later commentators as the locations of vital points, fatal and otherwise. Depictions of the skeleton were constantly refined in the course of the Qing, and from the mid-nineteenth century, they begin to show the influence of Western styles of illustration. ${ }^{48}$

These engravings of the skeleton reappear in the nineteenth century

47 Preface to Xiyuan lu jue (1831), juan 6, 1.

${ }^{48}$ On this subject, see Despeux 2005b. 

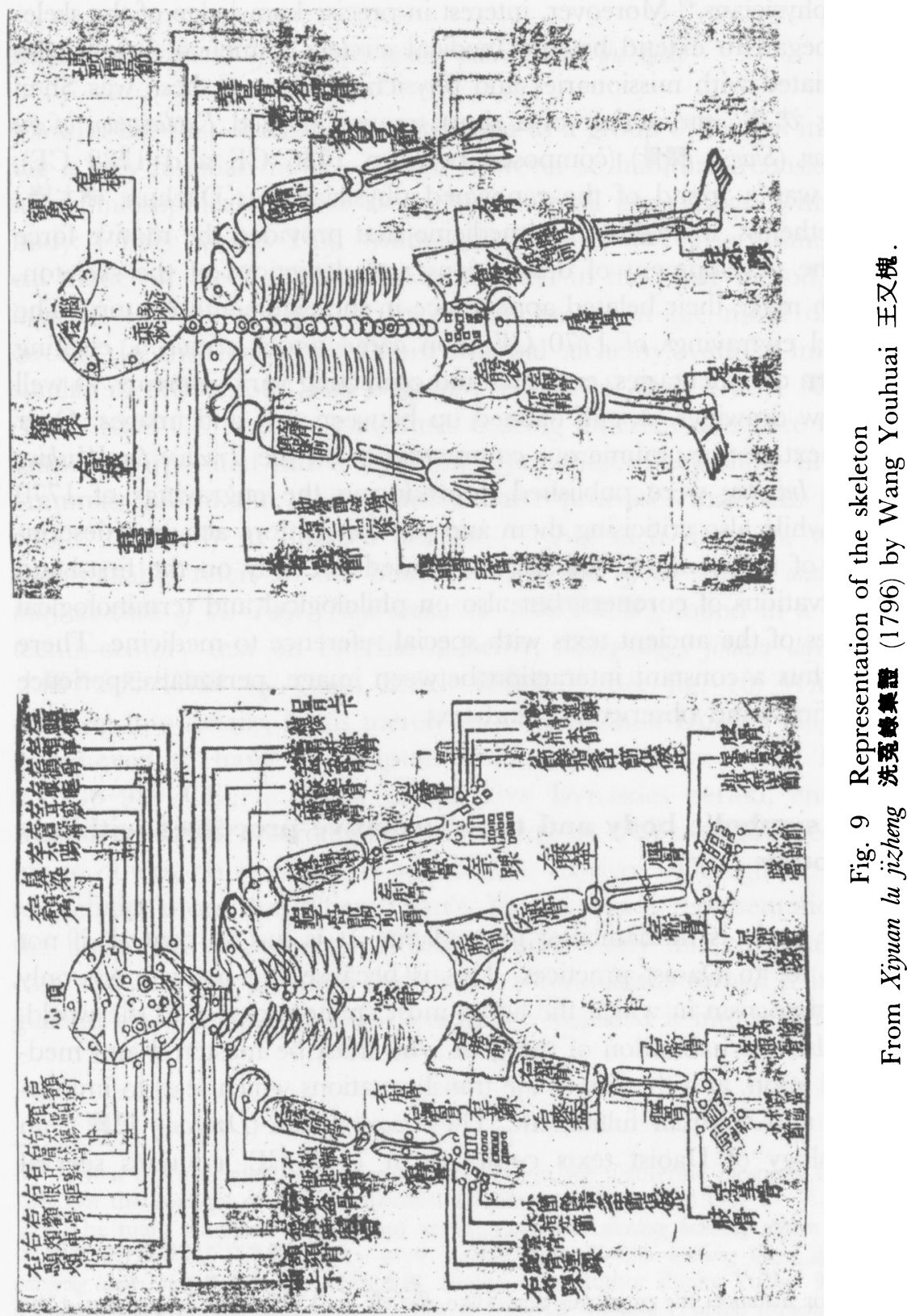
in two texts on traumatology. In fact, from the late Ming onward, there was a gradual rapprochement between coroners (wuzuo 仵作) and physicians.$^{49}$ Moreover, interest in precise knowledge of the skeleton began to extend beyond medical circles, to men of letters who associated with missionaries and physicians. One of these was Shen Tong 沈脤, the author of a short treatise entitled Explanation of the Skeleton (Shigu 釋骨) (composed between $1736 \mathrm{CE}$ and $1782 \mathrm{CE}$ ), who was a friend of the renowned physician Xu Dachun 徐大椿. Nonetheless, it was forensic medicine that provided the motive force for the development of descriptions and depictions of the skeleton, which make their belated appearance in the eighteenth century. The model engravings of $1770 \mathrm{CE}$ soon came under criticism, eliciting written commentaries, exposing and correcting various errors, as well as new drawings. A gulf opened up between text and images. Over the next century, numerous commentaries on the Treatise for Washing Away Injustice were published, reproducing the engravings of 1770 $\mathrm{CE}$, while also criticising them and providing more accurate descriptions of the bones of the skeleton, based not only on the first-hand observations of coroners, but also on philological and terminological studies of the ancient texts with special reference to medicine. There was thus a constant interaction between image, personal experience and first-hand observation, and text.

\section{The symbolic body and transformative processes within the body}

If the body is fundamental to medicine, it is just as central, if not more so, to Daoist practices. This is because the body is not only the microcosm in which the adept must create order as in the world, but also the habitation of the gods who must be mastered and meditated upon, and the site of the transformations which lead to immortality and spiritual fulfillment. The Daoist Canon (Daozang 道藏), an anthology of Daoist texts compiled in $1445 \mathrm{CE}$, contains several

${ }^{49}$ For instance, the physician Sun Yikui 孫一奎 (c. 1522-1619) incorporated the chapter from Xiyuan lu on the examination of bones into his Yizhi xuyu 紫旨緒余 Influence in the opposite direction is shown by the increasing frequency with which Qing commentaries on Xiyuan lu cite from medical sources. 
images of the body, all symbolic and all dating from no earlier than the Song. ${ }^{50}$

Alchemical diagrams of processes taking place inside the body

I would like first of all to draw attention to a group of images involving a very familiar motif, which is however so habitually considered in a philosophical context as to have lost all associations with the body: I refer to the Taiji symbol (Taiji $t u$ ) 太極圖. The cosmological model of the Taiji became established in the Song period, giving rise to various types of images all based on the motif of the circle. $^{51}$ In the context of Daoist internal alchemy, various images, similar to the famous Taiji Diagram (Taiji tu) of Zhou Dunyi 周敦願 (1017-1073 CE) though sometimes bearing different titles, are to be found incorporated into Ming and Qing texts. They show in diagrammatic form the main transformative processes that take place within the body in internal alchemy. ${ }^{52}$ One such diagram, which unmistakably refers to the body, is the Chart of the normal and contrary direction of the Taiji (Taiji shunni tu 太極順 逆圖), found in a fourteenth-century text on internal alchemy, Shangyangzi jindan dayao tu 上陽子金丹大要圖 by Chen Zhixu 陳致虚..$^{53}$ (See fig. 10) Without entering into details, let us merely recall that Zhou Dunyi's diagram is believed to have be adapted from an image by Chen Tuan (c. 906-989 CE), a Daoist of the Five Dynasties period, entitled Xiantian tu 先天圖 according to some sources or Wuji tu 無極圖 according to others, no examples of which have survived. Though we have no definite proof that Chen Tuan's Xiantian was a representation of the body and its processes, it seems highly likely that this was the case and that Zhou Dunyi and the Neo-Confucians turned it into a general cosmological model when they transposed it into a different

${ }^{50}$ For a more detailed discussion of this subject, see Catherine Despeux 2005a.

${ }^{51}$ On the concept of Taiji in internal alchemy, see Robinet 1990.

52 The main diagrams of this kind are Taiji miaohua shenling hundong chiwen zhi tu 太極妙化神雷混洞赤文之國. They were inserted into Yuanshi wuliang duren shangpin miaojing tongyi 元始無量度人上品妙經通耊 by the Ming author Zhang Yuchu 張宇初, a commentary on the Song text Scripture of Universal Salvation (Yuanshi wuliang duren

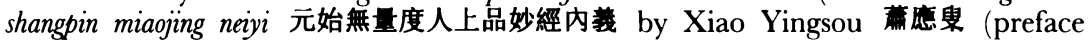
of 1226), $D z 89$ (fasc. 41-42), lb.

${ }^{53}$ Dz. 1068 (fasc. 738), 3a. 


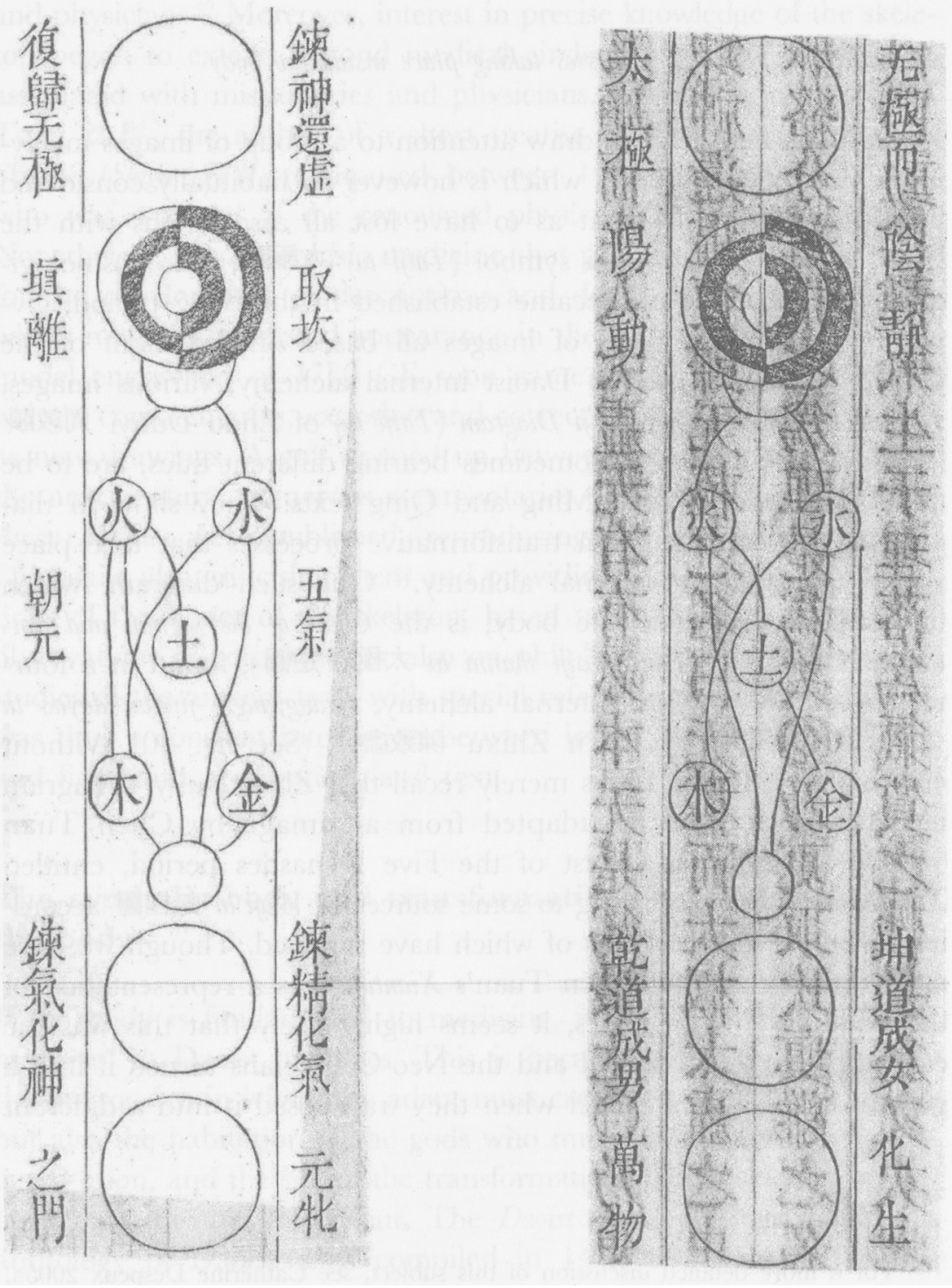

Fig. 10 Taiji tu 太極国 according to Chen Zhixu 致社.

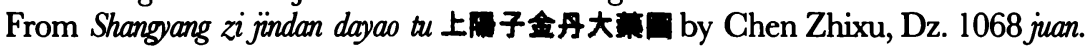


context. All the available versions of this image, whether they go by the name of Taiji tu 太極圖，Wuji tu 無極圖 or Xiantian tu 先天回， have certain features in common. First, the design is placed vertically on the page, although no hierarchy is thereby implied. It mingles visual elements and text, with a circle motif representing completeness and generally suggesting the idea of unity. The bipolar contrast of Yin and Yang is conveyed through the use of black and white. Written characters relate iconically to their referent-in the case of the Zhou Dunyi's image, the five agents of the five viscera, or in the Daoist images, the five ingredients of internal alchemy (cinnabar, silver, mercury, lead and earth). Connections between different elements of the image (viscera or agents) are shown by lines joining them together.

There is nothing in the title or appearance of the image to suggest that it has anything to do with the body; this transpires from the nature and composition of the texts that accompany it. The image itself shows only the main elements involved in the alchemical process: the spatio-temporal collocation, the route to be followed, the dynamics of the process, and the means of setting it in motion. The images are not susceptible to interpretation without an oral commentary or supporting text. Apart from the different kinds of inscriptions that they bear, Zhou Dunyi's Taiji $t u$ and the images from the internal alchemy tradition differ fundamentally in the direction in which they are required to be read: the former is read from top to bottom, the latter from bottom to top. This is confirmed in a commentary by Huang Zongyan 黄宗炎 (seventeenth century) ${ }^{54}$ on an image entitled $W u j i t u$ (the Never-Ending Image) and attributed to Ghen Tuan.

It would be a task far beyond the scope of this paper to compile an exhaustive list of all the images from the Daoist canon representing alchemical processes within the body. I will confine myself to citing the most important ones, which are contained in two texts dating from the Song and Yuan periods. The schema adopted here is particularly important: once again the contours of the body are not shown. The first of these texts is Xiuzhen taiji hunyuan $t u$ 修真太極混元圖, with its sequel Xiuzhen taiji hunyuan zhixuan tu 修真太極混元指玄圖, by Xiao

${ }^{54}$ See Yixue bianhuo, juan 2, 39b. 
Dacun 萧道存, ${ }^{55}$ which contains numerous diagrams illustrating various processes, most of which take place within the body. The same representational elements are used here as in the Taiji diagram: a circled character stands for an object (internal organ, sensory organ, location on the spinal column, etc.); the contrast between black and white symbolises the duality of Yin and Yang; there are lines showing connections; and there are occasional figurative elements. (See fig. 11) The second text is Daode zhenjing jiyi dazhi tuxu 道德真經集義大旨圖序,,$^{56}$ a collection of miscellaneous commentaries, some of them on alchemical subjects. It is certainly not earlier than the Yuan period. It contains illustrations based on maxims in Daode jing, which represent alchemical processes inside the body. (See fig. 12)

The true form of the symbolic body

In Daoist ceremonies and individual practices, the body figures as a sacred space, often visualised as a mountain or cave-womb complete with labyrinths, spirits and mansions. It is therefore essential that the adept should understand its true form and possess diagrams to guide him or her through it. Daoist representations of the body give information on the names of the principal spirits, key locations, processes and itineraries. The physical body gradually becomes the duplicate, or rather the Shadow, of the inner body, which constitutes the real or true (zhen 真) being as revealed in these diagrams. ${ }^{57}$ It is represented by the figure of a mountain, or in a form which suggests a body seen in profile or half-profile, with an arc representing the spine on the right-hand side and an open space on the left: it is not bounded by any kind of outline, and the distinction between inside and outside is almost effaced.

Diagrams, inscriptions, scraps of text, even some figurative elements all intermingle in a way that is richly suggestive of the ritual and magical function of visual images in Daoism. Far from being mere diagrams or maps, they possess the double force of word and image, conferring power on those who possess them or meditate

${ }^{55} \mathrm{Dz} 149$ and 150.

${ }^{56} \mathrm{Dz} 723$.

57 Compare Despeux 1996, pp. 87-118. 


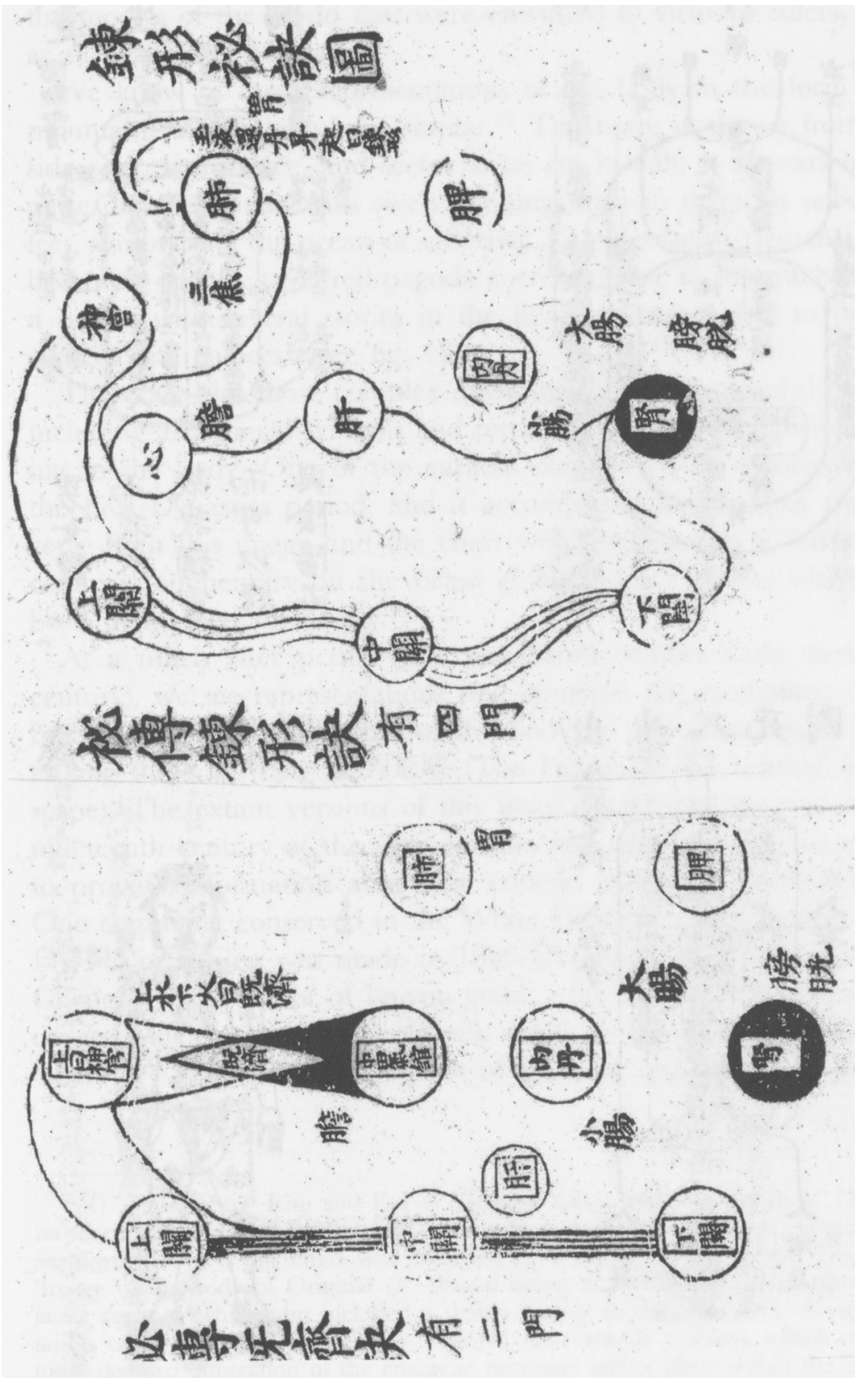

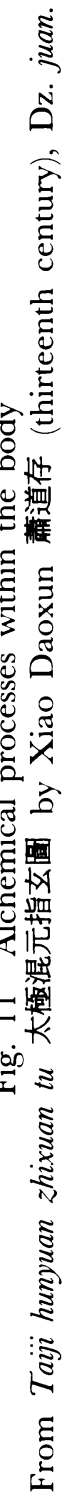



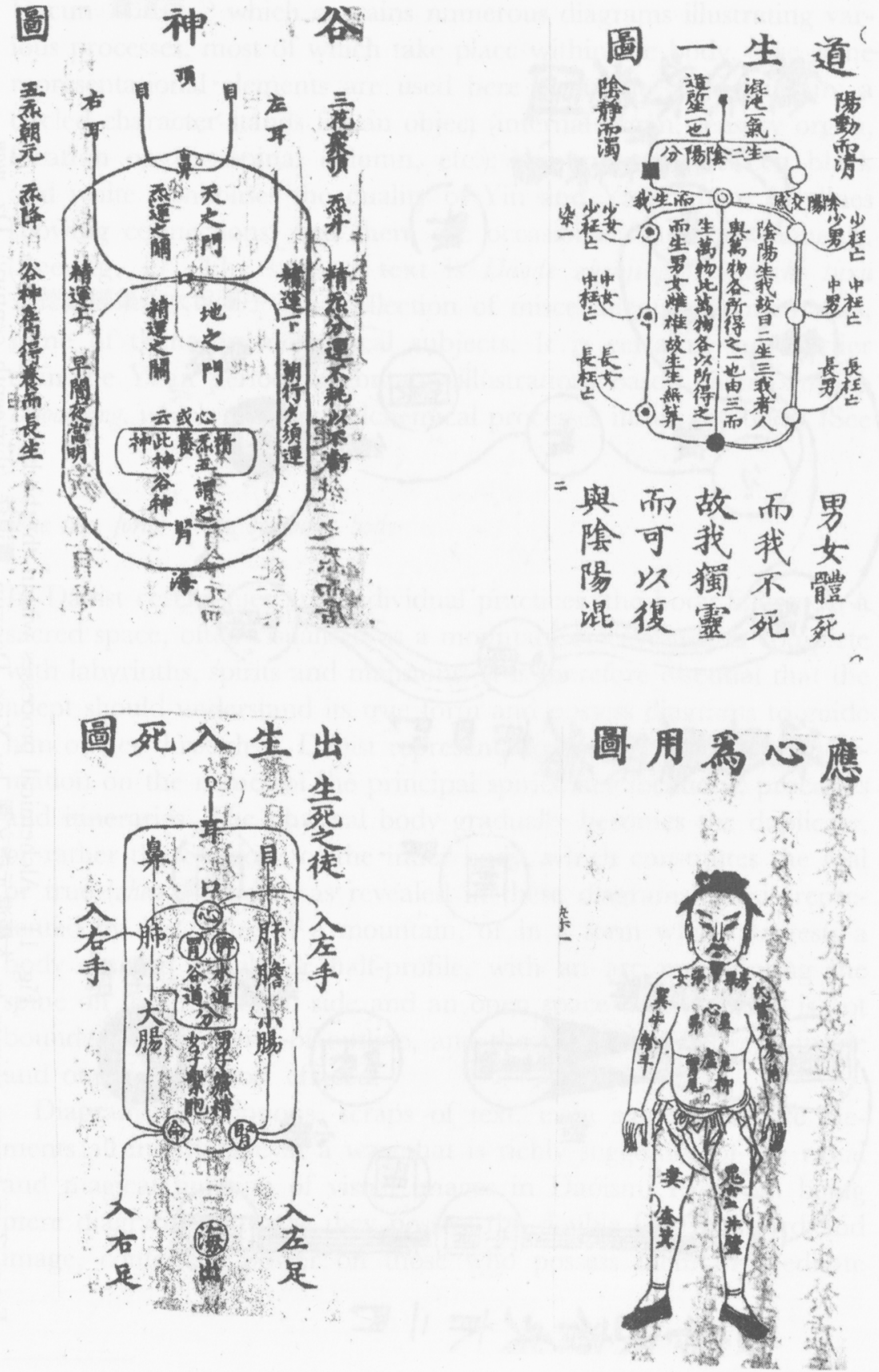

Fig. 12 Alchemical processes within the body

From Daode zhenjing jiyide zhixu tu 道德真經集一的圖, Dz. 723. 
upon them. They are thus akin to sacred scriptures, talismans and the models of the world that were entrusted to virtuous rulers, such as the Hetu and Luoshu.

We know of three representations of the body in the form of a mountain, all of them very similar. ${ }^{58}$ The body is shown from the side or in half-profile, and seems to be cut in half. It appears in the guise of a mountain with rivers running through it and a sea at its feet, symbolising the ocean of suffering. Two figurative elements may be noted: the twelve-tiered pagoda corresponding to the trachea and a palace with several stories in the head, corresponding to one of the celestial palaces. (See fig. 13)

There are also more complex drawings of the inscape of the body, including alchemical symbols and representations of the spirits residing in the body. One of the earliest examples is by Yanluo $\mathrm{Zi}$, of the Five Dynasties period, and it accompanies his chart of the viscera. Both this image and the chart were reprinted in a thirteenthcentury commentary on the Canon of Eighty-One Problems, which has been mentioned previously. ${ }^{59}$

At a much later period (late nineteenth century-early twentieth century), we see representations that combine the symbolism of the body as mountain with that of the body as inner landscape. Chief among these is Neijing $t u$ 內景圖 (The Picture of the Internal Landscape). The extant versions of this image date from the end of the nineteenth century at the very earliest, and are therefore too recent to provide information about the context in which it was created. One engraving conserved in the White Cloud Temple (Baiyun guan 白雲観) in Beijing was made in $1886 \mathrm{CE}$ on the instructions of Liu Chengyin, 20th abbot of Baiyun guan, who is supposed to have discovered the image on an old silk scroll in the Song mountains. ${ }^{60}$ There are also various exemplars of a Daoist image entitled Xiuzhen

58 1) 'Chart of the Rise and Fall of Yin and Yang, Image of the Body' ( $T i$ xiang yin yang sheng jiang tu 鰽象陰陽升降國), taken from Yuanshi wuliang duren shangpin miaojing neiyi, in which this chart was preceded by a design similar to the Taiji tu. 2) 'Image of the body of Original Qi' (Yuanqi tixiang tu 元乘體象回), from Shangyangzi jindan dayao $t u$, which also included a design similar to the Taiji $t u$. 3) A representation of the Daoyuan yiqi by Cao Yuanbai (seventeenth century), which offers a more detailed illustration of the energetic processes taking place within the body at different stages in the alchemical procedure.

59 Nanjing yiyi xulun, $D z .1024$.

${ }^{60}$ See Despeux 1994, pp. 44-8; Sakade 1991. 


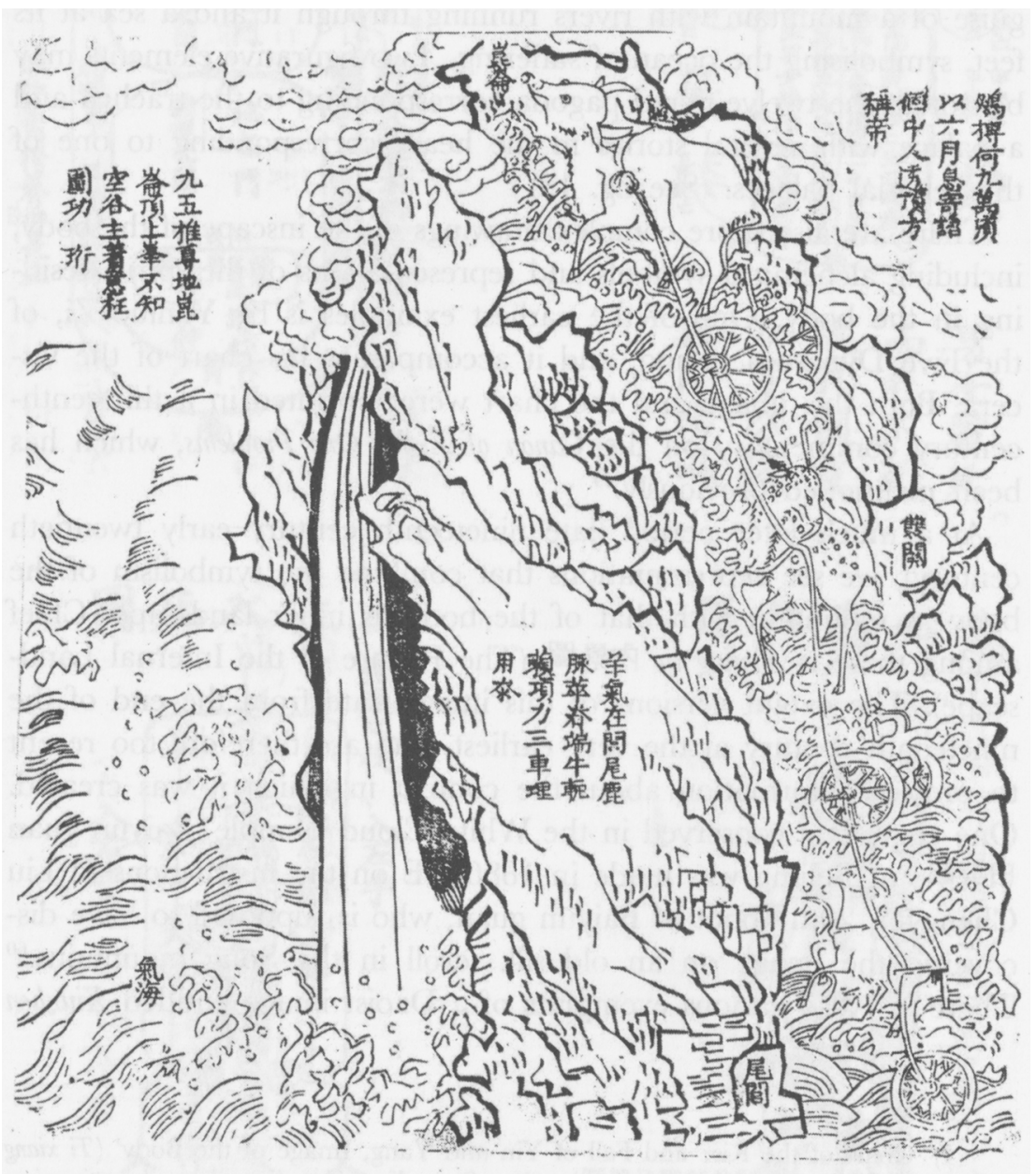

Fig. 13 Chart of the body as mountain showing alchemical processes From Daoyuan yiqi 道元一氣 by Cao Yuanbai 曹元白 (late sixteenth century). 
$t u$ 修真圖. Seven copies of this have so far been discovered, the earliest dating from $1812 \mathrm{CE}$. Even more than in the schema discussed above, these images combine visual and verbal signs to represent the body as physiological locus, internal landscape and habitation of the gods and demons. ${ }^{61}$

\section{Conclusion}

As I emphasised at the outset of this paper, although there are few extant images of the body predating the Song period, this does not mean that others never existed, but simply that they have not survived into the present. People had begun to feel the need for such images by the Han period at least. Nonetheless, the Song period clearly marks a turning point in the graphic representation of the body as in graphic representation $(t u)$ in general. From this time onward, visual imagery comes to play a more significant role, not only as a record of knowledge, but also as a teaching aid, a mode of transmission, a mnemonic device, a visual translation of a text and a representation of a certain reality.

What is immediately apparent from the images presented here is that they do not set out to reproduce visible reality. They are not pictures but diagrams or emblems, in which figurative concerns are subordinate to an ordered schematic arrangement, steering us towards an interpretation - a reading. For these coded representations, composed of conventional signifying elements, are meant to be read, in the same way that one reads a Chinese character. In fact, all the examples that we have explored include some form of lettering, and there is no clear demarcation between graphics and graphs. In Xiuzhen $t u$ - the concluding example - in particular, word and image are intimately intertwined. (See fig. 14)

The nature of representation is closely dependent on its function and utilisation. The body is represented with a complete outline when the divisions and sectors of the body are considered as parts of the whole, when it is important to identify exact locations in relation to the whole body, or when movement is involved (external

${ }^{61}$ On these images, see Despeux 1994; Lagerwey 1991, pp. 127-30. 


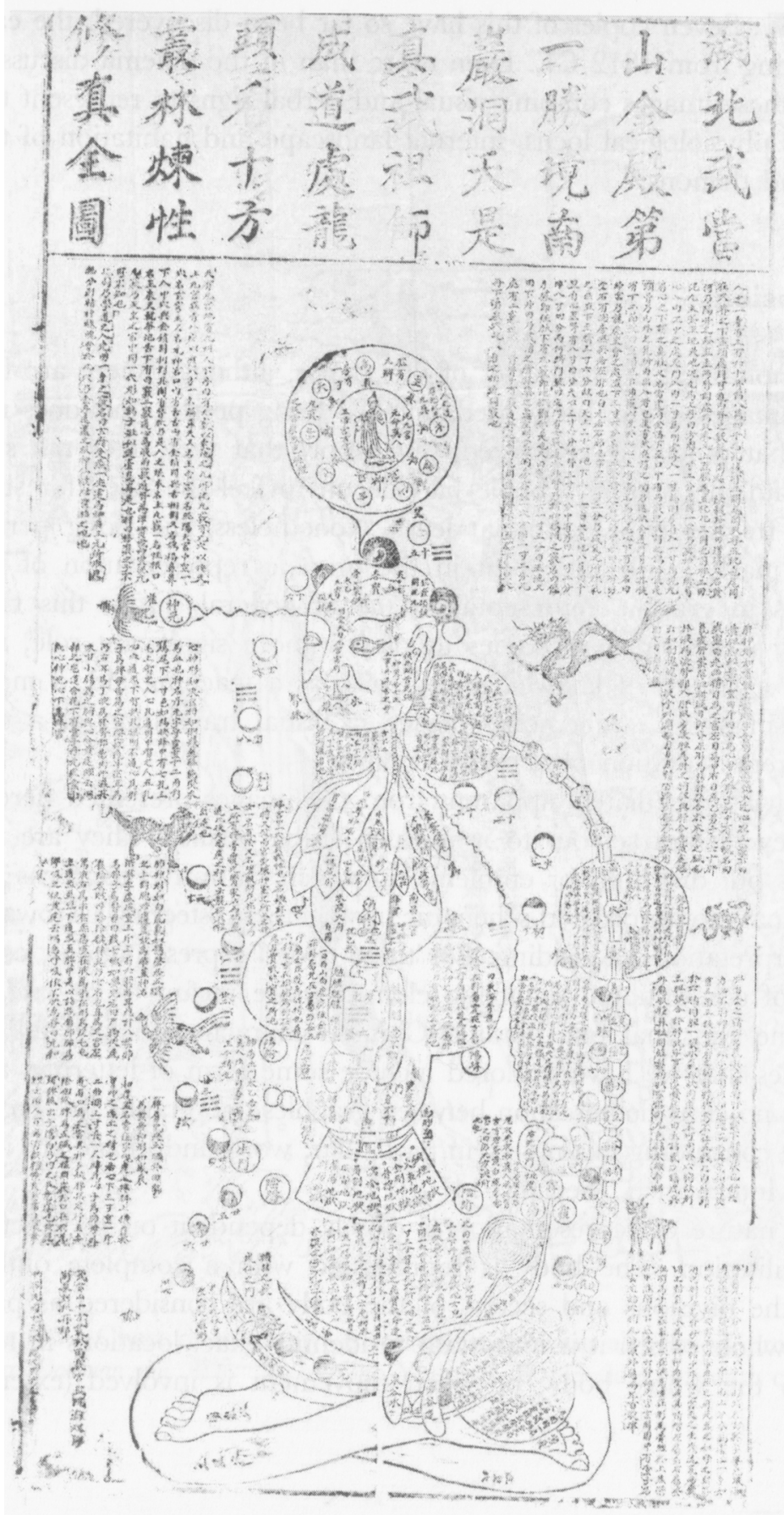

Fig. 14 Chart of the culture of perfection (Xiuzhen tu 修真国) (nineteenth century). 
movement in daoyin, or internal movements through the channels and tracts). An image of the body must be meaningful to its users, giving them a clearer understanding of their situation in space. A complete outline is useful to the practitioner, making it possible to locate the part of the body to be treated in physical space. It is required in general when the body is considered as a unit-as a selfcontained universe wherein $q i$, blood and other humours circulate. In these cases, there is a clear division between inside and outside. Undoubtedly, a bounded view of the body is inevitable, if the intention is to describe the circulation of matter in a closed, oriented space or to locate on a spatio-temporal map the points at which an external action or interpretation can be exercised. But these images are also the spatio-temporal mapping of a discourse, which must be read in context and in a genealogy of transmission. For instance, the first representations of the skeleton did not emerge from medicine; for the purposes of acupuncture it was sufficient to approach the bones from outside, and plot their approximate position on a chart of the body. On the other hand, advances in knowledge of the skeleton and in techniques of illustration were of benefit to forensic science, and were also taken up by physicians in the late Ming period. From a technical perspective, these representations are primarily memory aids. They are integral to a text and do not set out to be true to life. Chinese artists were perfectly capable of rendering physical objects faithfully and drawing an accurately proportioned human body. In the fine art tradition, virtuoso examples abound. But an artist-craftsman required to execute a schema, a $t u$, of the skeleton for forensic purposes would operate within the conventions of the genre, producing a stylised, generic image.

With representations of the viscera, both individual and composite, the didactic function of the image takes centre stage in the Song period, not only as an instrument for the transmission of knowledge but also as proof of an assertion, just as dissections in Europe served to demonstrate the ability of the practitioner. No doubt viscera charts were cited in the debates on the number of orifices in the throat and the position of the liver. One might however wonder what use this information could have been in clinical practice, since diagnostic and therapeutic principles did not adapt to accommodate the revised position of the liver, for example, and the liver pulse continued to be taken on the left. Surgery, which was almost non-existent, could not have stood to benefit from such advances in anatomical 
knowledge. Undoubtedly, all this reflects a desire to increase and enhance the sum of theoretical knowledge, but it also betrays a sense of dissatisfaction with the theoretical apparatus of medicine, which was unable to respond appropriately to some pathological conditions; the same dissatisfaction is articulated in other contexts by various physicians of the Song period, a time of acute analysis and reflection for Chinese thought in general.

Whereas depictions of the body in the technical domain are an adjunct to a textual exposition (medical, divinatory or forensic as the case may be), in Daoism, the graphic representation $(t u)$ becomes the true image (xiang) or icon of the body, realised according to the systems of the various schools. It is an object of power, like the talismans and diagrams used in rituals and individual practices ${ }^{62}$

As we have seen, the images examined are not mere representations of a certain reality. Like a written text, they act as carriers for a specific kind of knowledge and they are aimed at a specific user or readership. We lose sight of the body itself, as the spotlight falls on certain locations or landmarks on the reader's journey through the image, with respect to the inner world of the body or its relationship with the external world. The emphasis is placed on the mechanisms and operations underlying physical reality.

When one comes to consider the way in which the body is depicted, one is struck by the absence of flesh and muscle. We should certainly take into account the different relationship to the flesh that obtains in the West, due partly to Greek ideas on the role of muscle in the affirmation of personhood and nationhood, ${ }^{63}$ and partly to Christian thinking. However this difference is a matter of degree: Western attitudes have fluctuated over the course of history. To see the truth of this, one need only look at medieval images of the body. It was not until the sixteenth century that flesh and the body regained the importance they were accorded in ancient Greece and Rome, in sculpture in particular. But generally speaking, in China, flesh and muscle have had far less significance than $q i$, the invisible pneuma that brings life and motion. The Chinese did not set out to represent the movement of $q i$, but the arrangement in a given space of

${ }^{62}$ Compare Baptandier, 1994.

${ }^{63}$ Compare Pulmann's work on gymnastics in the West and the role of the Olympic Games. 
the viscera in which $q i$ was contained, together with their principal characteristics.

The treatment of the dichotomy between inside and outside does not constitute a distinguishing feature in images of the body. What counts is not the physical object we see before our eyes, but the various possibilities of transformation afforded by a dynamic vision of life. The body is recast in terms of motion, as the site of the circulation of $q i$ and blood, and the transformative mechanisms of Yin and Yang and the Five Agents; the inner landscape; the world of the gods and demons.

\section{References}

\section{Primary Sources}

Beiji qianjin yaofang 備急千金要方 (Emergency Prescriptions Worth a Thousand Gold Pieces), Sun Simiao 孫思遥, late seventh century CE.

Bintuilu 嘪退錄, edited in Shuofu.

Chongkan buzhu Xiyuan lu jizheng 重刊補注洗冤錄集證 (Revised and enlarged edition of Xiyuan lu), late eighteenth century CE.

Daozang 道藏 $[D z]$ (The Daoist Canon), compilation of 1445 CE.

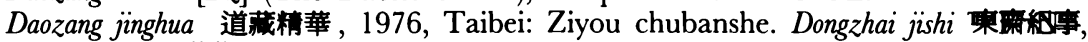
Fan Zhen 范鎮, $1087 \mathrm{CE}$.

$D z$, See Daozang.

Gujin yitong daquan 古今蜸通大全, Xu Chunfu 徐春甫, 1556 CE.

Hanshu 漠書 (History of the [Former] Han Dynasty).

Hua Tuo xuanmen neizhao tu 華 陀玄門內照圆 (Hua Tuo's Chart of Inner Contemplation [of the body] According to the Mystery School), published by Sun Huan 孫焕 in 1273 CE. Huangdi neijing 黃帝內經 (Inner Classic of the Yellow Emperor).

Jutan lu 㓺談錄, Kang Pian 康研 (fl. 875-886).

Mengqi bitan 夢溪筆談, Shen Gua 沈括, 1094 CE, edited by Hu Daojing 胡道靜, in Mengqi bitan jaaozheng 夢慀筆談校證, 1956, Shanghai: Shanghai chuban gongsi.

Shuofu 說郛, Tao Zongyi 陶宗雔 (fl.1360-68 CE).

Siku quanshu 四庫全書, late eighteenth century CE.

Suishu 隋書 (History of the Sui Dynasty).

Sui Tang jiahua 隋唐佳話.

Xin Tangshu (New History of the Tang Dynasty).

Xiuzhen shishu 修真十晴, Daoist encyclopaedia of c. $1250 \mathrm{CE}$.

Xiyuan lu 洗冤錄 (Treatise for Washing Away Injustice), Song $\mathrm{Ci}$ 末慈, thirteenth century CE.

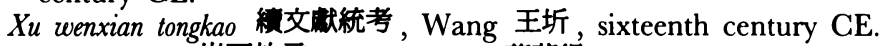

Yanxia fangyan 岩下放言, Ye Mengde 菜夢得 (1077-1148 CE), edited in Shuofu.

Yilin gaicuo 林改錯 (Corrections of the Errors in the Forest of Medicine), Wang Qingren 王清任, 1822 CE.

Yixue bianhuo 易學辨惑, Huang Zongyan 黃宗炎, in Zhaodai congshu.

Yuandian zhang 元典章 (the Yuan Code), edited by Shen Jiaben 沈家本, 1322 CE. Zhaodai congshu 昭代對春, early seventeenth century CE.

Zhenjiu Dacheng 針炎大成 (Compendium of Acupuncture and Moxibustion), Yang Jizhou 楊耝州, $1601 \mathrm{CE}$. 


\section{Secondary Sources}

Baptandier, Briggite 1994, 'Le tableau talismanique de l'empereur de jade. Construction d'un objet d'écriture', L'Homme, 129: 59-92.

Chen Guofu 陳國符 1963, Daozang yuanliu kao 道藏原流考, Beijing: Zhonghua Shuju. Despeux, Catherine 1985, Prescriptions valant mille onces d'or, Paris: Guy Trédaniel.

- 1988, La moelle du phénix rouge. Santé et longue vie dans la Chine du XVI siècle, Paris: Guy Trédaniel.

- 1989, 'Gymnastics: The Ancient Tradition', in Livia Kohn and Sakade Yoshinobu (eds) Taoist Meditation and Longevity Techniques, Ann Arbor: Center for Chinese Studies, University of Michigan.

1994, Taoisme et corps humain. Le Xiuzhen tu, Paris: Guy Trédaniel.

1996, 'Le corps en Chine, champ spatio-temporel, souche d'identité', L'Homme, 137: $87-118$.

2004, 'La gymnastique dans la Chine antique', Etudes chinoises, 23.

- 2005a, 'Alchimie symbolique et du corps dans la Chine du Moyen Âge $(\mathrm{X}-\mathrm{XIV}$ c siècles)', in Claire Kappler and Suzanne Thiolier (eds) Alchimie: OrientOccident, Paris: Dervy Livres.

- 2005b, 'The body revealed. The contribution of forensic medicine to knowledge and representations of the skeleton in China', in Georges Métailié and Francesca Bray (eds) Techniques and Visual Representations (forthcoming)

Goldschmidt, Asaf 2005, 'The Song discontinuity: Rapid innovation in Northern Song dynasty medicine', Asian Medicine, Tradition and Modernity, 1, 1: 53-90.

Grmek, Mirko and Raffaele Bernabeo 1997, 'La machine du corps', in Mirko Grmek (ed.) Histoire de la pensée médicale Volume 2, De la renaissance aux lumières, Paris: Seuil.

Harper, Donald 1998, Early Chinese Medical Literature: The Mawangdui Medical Manuscripts, London and New York: Kegan Paul International.

Jia Jingtao 賈景陶 1983, 'Liangbu zhongyaode fayixue wenxian Yanshi gemu jie'anshide faxian' (Discovery of two major documents of forensic medicine: Legal models and engravings of the skeleton), in Fayi tongxun 法掣通讯 4.1.

Lagerwey, John 1991, Le continent des esprits. La Chine dans le miroir du taoïme, Bruxelles: La renaissance du livre.

Lo, Vivienne 2005, 'Quick and easy Chinese medicine: the Dunhuang moxibustion charts', in Vivienne Lo and Christopher Cullen (eds) Medieval Chinese Medicine: The Dunhuang Medical Manuscripts, London and New York: Routledge Curzon, 207-51.

Ma Jixing 馬䋖 興 1993, Zhenjiu tongren yu tongren xuefa 針众銅 人與銅人穴法, Beijing: Zhongyiyao chubanshe.

Miyashita Saburô 宮下三郎 1968, 'Sogennô iryô 宋元の医康' (Medical theory under the Song and the Yuan), in Soggen jüdaino kagaku gijitsu shi 宋元時代の科学技術史, edited by Yabuuchi Kiyoshi, Kyoto, Kyoto digaku jimbun kagaku kenkyujyo.

Okanishi Tameto 岡西爲人 1958, Song yiqian yiji kao 末以前㹂籍 考 (Study of the medical documents through the Song period), Beijing: Renmin weisheng chubanshe.

Ratchnevsky, Paul 1937, Un Code des Yuan, Paris: E. Leroux.

Robinet, Isabelle 1990, 'The place and meaning of the notion of Taiji in Taoist sources prior to the Ming dynasty', History of Religions, 29, 4: 373-411.

Sakade Yoshinobu, 1991, 'Naikeizu to sono enkaku 内景图とその沿革', in Chugoku kodai kagaku shiron besatsu 中国古代科学史論別冊，Kyoto: Kyoto daigaku, jinbun kagaku kenkyujyo.

Unschuld, Paul 1985, Medicine in China, Berkeley, Los Angeles, London: University of California Press. 